\title{
A Usina Hidrelétrica de Belo Monte (Altamira, Estado do Pará, Norte do Brasil), o reassentamento urbano coletivo e a avaliação de impactos ambientais
}

\section{Lucas dos Santos Alves ${ }^{1}$, Sara Nayara da Silva Hage ${ }^{1}$, Antônio Pereira Júnior ${ }^{2}$}

${ }^{1}$ Curso de Engenharia Ambiental. Universidade do Estado do Pará. Departamento de Engenharia Ambiental. Avenida Hileia, S/№. Amapá. Marabá-PA, Brasil (CEP 68502-100).

${ }^{2}$ Universidade do Estado do Pará. Departamento de Engenharia Ambiental. Avenida Hileia, S/№. Amapá. Marabá-PA, Brasil (CEP 68502-100). E-mail: antonio.junior@uepa.br.

Resumo. As construções de usinas hidrelétricas muitas vezes causam desequilíbrio ambiental, social, além dos reassentamentos urbanos que são geradores de impactos ambientais. 0 objetivo deste trabalho foi avaliar, identificar e interpretar qualiquantitativamente os impactos ambientais na área que compreende o Reassentamento Urbano Coletivo (RUC) São Joaquim, Bairro São Joaquim, Altamira, Estado do Pará, Norte do Brasil. 0 método aplicado foi o hipotético-dedutivo, com pesquisa exploratória, observativa, sistemática, direta, executada em três etapas distintas, (1) levantamento de dados documentais com recorte temporal compreendido entre 2008 a 2017; (2) dez visitas técnicas para caracterizar os meios físicos, bióticos e antrópicos, bem como as respectivas alterações causadas nesses meios, por fontes antrópicas, e os impactos positivos e negativos; e (3) 30 entrevistas informais para identificação de pontos chaves da situação atual do reassentamento, posterior elaboração e aplicação de 150 formulários mistos, in loco, para a identificação da percepção ambiental desta comunidade e da qualidade ambiental da localidade. Os dados obtidos e analisados indicaram que a qualidade de vida desses indivíduos melhorou $(86,6 \%)$ e citaram a infraestrutura ofertada como um benefício ao deslocamento involuntário. Os impactos negativos (76\%) e positivos (24\%) foram distribuídos nos três meios (biótico, físico e antrópico), entre eles, a disposição inadequada de resíduos sólidos no reassentamento ( $\mathrm{V}=-9$; $\mathrm{S}$ : Média). Todavia, os impactos ambientais e socioeconômicos ainda persistem no RUC São Joaquim e necessita que sejam aplicadas políticas públicas voltadas para a sua diminuição.

Palavras-chave: Deslocamento involuntário; Matriz de impacto; Qualidade de vida.

Recebido:

$12 / 03 / 2018$

Aceito:

$23 / 04 / 2018$

Publicado:

$30 / 04 / 2018$

Acesso aberto

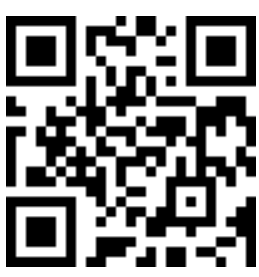

ORCID

(1) 0000-0003-2093-0443 Lucas dos Santos Alves

D 0000-0003-2326-911X Sara Nayara da Silva Hage

(1) 0000-0003-6241-985X Antônio Pereira Júnior 


\begin{abstract}
The Belo Monte Hydroelectric Power Plant (Altamira, Pará State, North Brazil), collective urban resources and environmental impact assessment. The construction of hydroelectric power plants often causes environmental and social imbalance and urban resettlement which generates environmental impacts. The objective of this study was to evaluate, identify and interpret the environmental impacts, qualitatively and quantitatively, in the area comprising the Collective Urban Resettlement (RUC) São Joaquim, located in the São Joaquim Neighborhood, in the municipality of Altamira, Pará State, North Brazil. A hypothetical-deductive method was applied based on an exploratory, observational, and systematic direct research, carried out in three distinct stages: (1) documentary data survey from 2008 to 2017; (2) ten technical visits to characterize the physical, biotic and anthropogenic resources and the respective changes caused by anthropogenic sources, as well as the positive and negative impacts; and (3) thirty informal interviews to identify key points of the resettlement current situation, and subsequent elaboration and application of 150 mixed questionnaires, in loco, to identify the environmental perception of the community and environmental quality of the locality. The data obtained and analyzed in this study indicated that the quality of life of the individuals improved (86.6\%) and, according to community residents, the infrastructure offered is a benefit to involuntary displacement. Both negative (76\%) and positive (24\%) impacts were distributed in the three environments (biotic, physical and anthropic), among them, the inappropriate disposal of solid wastes in the resettlement ( $V=-9$; S: Average). However, the environmental and socioeconomic impacts persist in the RUC São Joaquim; therefore, public policies aimed at reducing these impacts are needed.
\end{abstract}

Keywords: Involuntary displacement; Matrix of impact; Quality of life.

\section{Introdução}

Existe hoje no Brasil um intenso debate a respeito da construção de usinas hidrelétricas - UHE's, na região amazônica. A instalação de barragens muitas vezes causa desequilíbrio ambiental e social às regiões afetadas, em virtude de desmatamento, de deslocamento de populações e de alagamento de áreas florestais e de propriedades. Por outro lado, a energia gerada por UHE's é parte essencial da matriz energética do Brasil, produzindo atualmente mais de $60 \%$ da eletricidade consumida no país (Assunção et al., 2016).
Ademais, a construção de uma usina hidrelétrica ocasiona vários impactos, tantos sociais como ambientais, entre os sociais está o deslocamento de pessoas/famílias de suas residências em razão de estarem em um local que será direta ou indiretamente afetado com a referida obra (Sánchez, 2008). Porém, a imprevisibilidade e a imprecisão do planejamento prévio são marcas presentes no processo de identificação dos atingidos que necessitam de reassentamento urbano, configurando-se em lógica de produção de políticas compensatórias que desconsidera - ou desconhece - a própria dinâmica de 
produção das demandas e dos conflitos em cenários de grandes projetos, nas quais as (supostas) medidas de inclusão revestem-se, institucionalmente, em mecanismos de classificação arbitrária dos não incluídos, que são excluídos do reconhecimento como sujeitos do direito a compensações e/ou mitigações (Oliveira et al., 2014).

Atualmente, as declarações de utilidade pública das áreas destinadas ao reassentamento das populações deslocadas em razão da implantação de usinas hidrelétricas - processo que abrange a construção do canteiro de obras, o enchimento dos reservatórios, a criação de áreas de preservação ambiental, e outro - são emitidas pela Agência Nacional de Energia Elétrica ANEEL, a pedido dos empreendedores, como condição para a promoção das desapropriações, das áreas destinadas a esse fim (Ferreira, 2009).

Os reassentamentos são promotores dos deslocamentos espaciais. A compreensão das consequências desses deslocamentos espaciais no ser humano é de fundamental importância para o aprofundamento das necessidades humanas envolvidas no ato de projetar, pois possibilita a melhor elaboração do processo projetual a fim de que a habitação social atenda de modo satisfatório. Nos remanejamentos/ reassentamentos, pesquisadores de diversas áreas do conhecimento voltados para 0 assunto apontam os deslocamentos espaciais como uma experiência que possibilitam implicações espaciais importantes na saúde do ser humano (Graim et al., 2017).

Neste contexto, os estudos ambientais que envolvam o deslocamento de pessoas devem dedicar uma atenção especial ao programa de reassentamento da população (Freitas et al., 2013; Miranda Neto, 2014; Pozzatti Junior e Ribeiro, 2014). No passado, esses projetos somente pagavam indenização pelo valor da propriedade e das benfeitorias afetadas, por exemplo, no caso de desapropriação para fins de utilidade pública.

Quanto à Avaliação de Impactos Ambientais (AIA), internacionalmente, o referido termo é bastante dinâmico e pode variar conforme a situação em que será aplicado. De forma resumida, a International Association for Impact Assessment (IAIA), define avaliação de impactos como o processo de identificar as consequências futuras de uma ação presente ou proposta (IAIA, 2016).

Nacionalmente, a definição de impacto ambiental consta na Resolução CONAMA no 001/1986, como qualquer alteração das propriedades físicas, químicas e biológicas do meio ambiente resultantes de atividades humanas que, direta ou indiretamente que afetem a saúde, a segurança, e o bem-estar da população; as atividades sócias e econômicas; a biota; as condições estéticas e sanitárias do meio ambiente e a qualidade dos recursos ambientais (Brasil, 1986).

Enfim, os problemas causados à população como o deslocamento involuntário durante a construção de UHE's, desfazem os vínculos socioculturais construídos sob hereditariedade familiar, além de impactos no meio biofísico. Tais acontecimentos justificam a aplicação da presente pesquisa, cujo objetivo é uma promover uma avaliação qualiquantitativa, a identificação dos impactos ambientais, a percepção ambiental da comunidade ali residente e propor três medidas mitigatórias aos impactos identificados e classificados.

\section{Fundamentação teórica}

\section{coletivos}

\section{Reassentamentos urbanos}

0 remanejamento/reassentamento de uma população não pode ser considerado isoladamente, como um mero projeto de obras, uma vez que afeta não somente a vida das famílias envolvidas e a área objeto de intervenção, mas todo o entorno social e 
urbanístico. O local de reassentamento deverá ser, sempre que possível, próximo à área original, em respeito aos laços de vizinhança e trabalho já estabelecidos. Deverá ainda ser servido de infraestrutura básica e equipamentos comunitários, que atendam à demanda da comunidade reassentada (Brasil, 2010).

Em um programa habitacional de qualidade urbana, incluindo os reassentamentos, deve-se dar importância não só à estrutura habitacional em si, mas também o que há ou não em seu entorno, como o bairro, vizinhança, área de lazer, equipamentos públicos, entre outros. Este habitar trata de "uma entidade que se prolonga, sequencialmente, da casa à cidade, e vive no micro tecido urbano das cadeias de vizinhanças que constituem o contínuo de uma cidade estimulante e coesa" (Coelho e Pedro, 2013).

0 reassentamento surgiu como uma resposta aos problemas causados pelo deslocamento de quantidades crescentes de pessoas e como uma resposta à oposição encontrada pelos promotores de muitos projetos que implicavam o deslocamento forçado. Trata-se de uma ação planejada de deslocamento, transferência e reinstalação involuntária de pessoas e suas atividades em um novo local - uma medida mitigadora e compensatória de alguns impactos negativos causados. As populações afetadas podem ser rurais ou urbanas. 0 novo local deve ser apto para que as comunidades reassentadas possam continuar a exercer suas atividades e, se possível, deve fornecer melhores condições de infraestrutura e serviços (Sánchez, 2008).

\section{o deslocamento involuntário para RUC's - causas}

Dentre as várias causas para o deslocamento involuntário de comunidades na Amazônia, a principal é a construção de hidrelétricas. A primeira delas, nesta região, assentou-se no Município de Presidente Figueiredo - AM, denominada Balbina, cuja construção foi efetivada no final dos anos 1980, onde à época poucas pessoas habitavam a área. Havia no local comunidades indígenas, camponeses, sitiantes fazendeiros, arrendatários e trabalhadores rurais (Brandão, 2010).

Outro exemplo foi o assentamento da Usina Hidrelétrica de Tucuruí, onde houve o deslocamento de 23.871 pessoas. Trinta anos depois, muitos não receberam qualquer compensação (Fearnside, 2015).

Todavia, durante a implantação das usinas hidrelétricas, milhares de famílias perderam suas terras e casas, deixaram de ser reassentadas, ou foram assentadas em terras com baixa fertilidade. Outras receberam indenizações, mas não conseguiram comprar novas terras, em virtude do valor irrisório recebido. Um caso típico dessas perdas ocorreu em Tucuruí, pois pescadores à jusante do Rio Tocantins, perderam seus meios de vida sem ser compensados pela perda (Mendes e Hespanhol, 2012).

\section{Impactos ambientais}

Neste contexto, o termo impacto ambiental, apesar de ser amplamente empregado para referir-se a aspectos negativos decorrentes de ação antrópica, pode possuir conotação positiva. Isto ocorre devido ao fato de que um impacto pode ocorrer na forma negativa como na forma positiva, isto é, trazer malefícios ou benefícios, respectivamente (Meneguzzo e Chaikouski, 2010).

\section{Impactos ambientais causados pelos RUC's}

Data de 1980 a adoção pelo Banco Mundial de sua primeira política sobre reassentamento involuntário, que preconizava um tratado sistemático da questão, levando em conta os impactos sobre as populações diretamente afetadas. Fundamental para essa política era o planejamento prévio do reassentamento, visando reproduzir no novo local, condições similares àquelas 
experimentadas pela população no seu local de origem, mas ainda em 1980, a política adotada pelo Banco Mundial não fazia mais do que refletir a inquietação e a resistência ativa de muitas comunidades atingidas por projetos que forçavam seu deslocamento (Sánchez, 2013).

Segundo o relatório da Comissão Mundial de Barragens, as estimativas globais sugerem entre 40 e 80 milhões de pessoas deslocadas pelas barragens. Devido à importância do conhecimento sobre a quantidade de atingidos e especialmente a quantidade de reassentados (aqueles que passaram a morar em outras localidades), após construção de barragens e enchimento dos reservatórios), identificamos como primeiro impacto a quantidade de pessoas reassentadas (Bedoya et al., 2016).

\section{Avaliação de Impactos Ambientais - AIA \\ A Avaliação de Impacto} Ambiental foi instituída inicialmente nos Estados Unidos através da National Environmental Policy Act (NEPA), aos projetos governamentais e empreendimentos privados que dependiam de autorização ou financiamento do governo (Santos e Fiori, 2010).

No Brasil, apesar da Avaliação de Impactos Ambientais e Licenciamento Ambiental, instrumentos da Política Nacional de Meio Ambiente (Lei no 6.938/1981), representarem um marco histórico para a prevenção e controle dos impactos ambientais decorrentes do desenvolvimento, ainda há a necessidade de estruturação sistemática da participação do setor saúde neste processo, através da criação de instrumentos que contribuam para induzir as empresas a mitigar e compensar seus impactos à saúde da população (Silveira, 2008).

\section{Métodos de avaliação}

Há uma grande diversidade de métodos de avaliação de impactos envolvendo diferentes abordagens, como, por exemplo, os métodos baseados em cartografia, em modelagem matemática de ecossistemas, em valoração econômica do meio ambiente e outros critérios (Farinaccio e Tessler, 2010).

Dentre eles, destacam-se, as matrizes de interação por serem bastante utilizadas. A primeira matriz de interação foi elaborada por Leopold et al. (1971), também chamada de Matriz de Leopold, desenvolvida inicialmente para projetos de mineração (Gomes, 2009), baseada em uma lista de 100 ações com potencial de possíveis causadores de impacto ambiental e 88 características ambientais (Finucci, 2010).

É importante mencionar que, para realizar a avaliação de impacto ambiental, há uma metodologia. Ela consiste em um conjunto de normas que variem de acordo com o fator ambiental considerado, além de serem métodos flexíveis, aplicáveis em qualquer fase do processo e revisados constantemente (Cremonez et al., 2014).

\section{Medidas ambientais}

As medidas ambientais são ações propostas com finalidade de reduzir a magnitude ou a importância dos impactos ambientais adversos. Medidas mitigadoras "são o conjunto de procedimentos metodológicos capazes de minimizar e/ou evitar: I) os efeitos difusos dos impactos negativos da atividade licenciada; II) o agravamento de impactos identificados e; III) a ocorrência de novos impactos" (Walter, et al., 2012). Desta forma, a exigência de medidas mitigadoras e compensatórias como parte do licenciamento ambiental, é prevista na Resolução CONAMA no 001/1986 (Brasil, 1986).

O Plano Básico Ambiental (PBA), elaborado para a Usina Hidrelétrica de 
Belo Monte, delimitou as ações para a execução da obra e das medidas mitigatórias. Com a opção pelo reassentamento, mais de 22.000 pessoas deveriam ser assentadas em mais de 6.000 lotes urbanos. Os critérios utilizados pela Norte Energia para a seleção dessas áreas foram a localização (priorizando áreas de até $2 \mathrm{~km}$ do local de origem dos assentados), acessibilidade (comunicação com 0 entorno a partir de um sistema viário funcional), topografia favorável (além de estar acima da cota de segurança, o terreno deveria possuir poucas variações topográficas, com condições para uma drenagem adequada), conexão com as estruturas básicas mínimas (saúde, educação e serviços básicos), bem como as condições de aquisição e disponibilidade no mercado (Norte Energia, 2011).

\section{Material e métodos} Altamira

Fisiografia do Município de

O Município de Altamira (coordenada geográfica de referência $3^{\circ} 12^{\prime} 28.79^{\prime \prime} \mathrm{S}$ e $52^{\circ} 12^{\prime} 50.93^{\prime \prime} \mathrm{N}$ ) está localizado no oeste do Estado do Pará, distante $450 \mathrm{~km}$ em linha reta da capital do estado, Belém, ou $818 \mathrm{~km}$ por via rodoviária na rota de Tucuruí-Lindeiro. A dois dos eixos de transportes, o território municipal de Altamira recebe influência da Rodovia Transamazônica (BR-230), em sua porção norte, e à oeste da Rodovia BR-163. De acordo com os dados do Instituto Brasileiro de Geografia e Estatística - IBGE, esse município possui área de aproximadamente $159.533 \mathrm{~km}^{2}$, e população, estimada em 2017, de 111.435 habitantes. Além disso, está inserido em um dos mais ricos biomas brasileiros em biodiversidade, a Amazônia (IBGE, 2017; PMA, 2011).

A temperatura média anual no município é de $26^{\circ} \mathrm{C}$, com máxima de $31^{\circ} \mathrm{C}$ e mínima de $21,9{ }^{\circ} \mathrm{C}$. Com alto volume de precipitações mensais, a umidade relativa média mensal de Altamira é alta, $84 \%$. 0 período de menor umidade relativa, com significativa diminuição das chuvas, abarca os meses de julho a novembro de cada ano. Assim, a média de precipitações é de $55,5 \mathrm{~mm}$ de julho a novembro, mas alcança a média de 287,1 $\mathrm{mm}$, de dezembro a junho (PMA, 2011).

\section{Área de estudo}

A área objeto desta pesquisa é o Reassentamento Urbano Coletivo (RUC) São Joaquim, localizado a aproximadamente $2 \mathrm{~km}$ do centro de Altamira $\left(3^{\circ} 11^{\prime} 37,21^{\prime \prime} \mathrm{S}\right.$ e $52^{\circ} 13^{\prime} 51,35^{\prime \prime} \mathrm{O}$, $3^{\circ} 11^{\prime} 36,42^{\prime \prime} \mathrm{S}$ e $52^{\circ} 13^{\prime} 29,90^{\prime \prime} \mathrm{O}$, $3^{\circ} 12^{\prime} 3,28^{\prime \prime} \mathrm{S}$ e $52^{\circ} 13^{\prime} 32,22^{\prime \prime} \mathrm{O}$, $3^{\circ} 11^{\prime} 59,08^{\prime \prime}$ S e $52^{\circ} 13^{\prime} 55,45^{\prime \prime}$, na área urbana do município (Figura 1), que recebeu 827 famílias, entre ribeirinhos, comunidades tradicionais, quilombolas, pescadores, etc.

O RUC São Joaquim foi escolhido como local de estudo em razão de ser um dos reassentamentos em que houve um alto índice de supressão da vegetação (impacto ambiental severo) para urbanização e soerguimento de unidades arquitetônicas, aproximadamente 40 ha de floresta foram suprimidos. Vale ressaltar que, antes da implantação do RUC São Joaquim, a área em questão era caracterizada por ser mista, com trechos de pastagens e áreas de floresta (Figura 2a), e do reassentamento com infraestrutura civil (Figura 2b). 


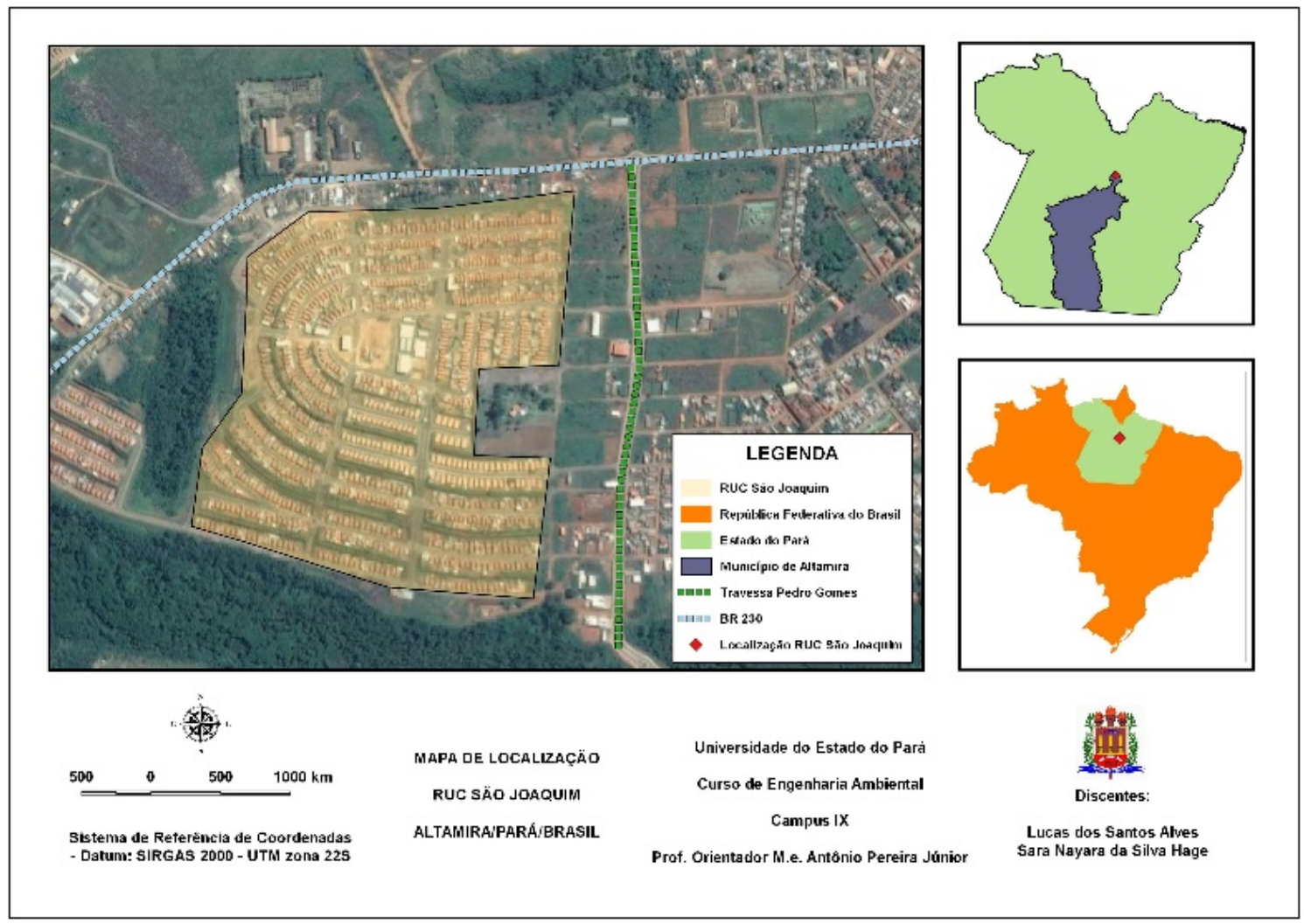

Figura 1. Localização cartográfica do Reassentamento Urbano Coletivo São Joaquim. Altamira-PA. Fonte: autores (2017).

De acordo com informações cedidas por um funcionário da Secretária Municipal da Gestão do Meio Ambiente e Turismo de Altamira- SEMAT, em que o mesmo acompanhou in situ todo o processo de Licenciamento do Reassentamento Urbano Coletivo São Joaquim, o projeto foi elaborado pela empresa Worley Parsons, terceirizada da Norte Energia SA, empresa de Sociedade de Propósito Específico, SPE, e responsável pela implantação e operação da Usina Hidrelétrica Belo Monte. Todo o processo de licenciamento do reassentamento aconteceu naquela Secretaria.

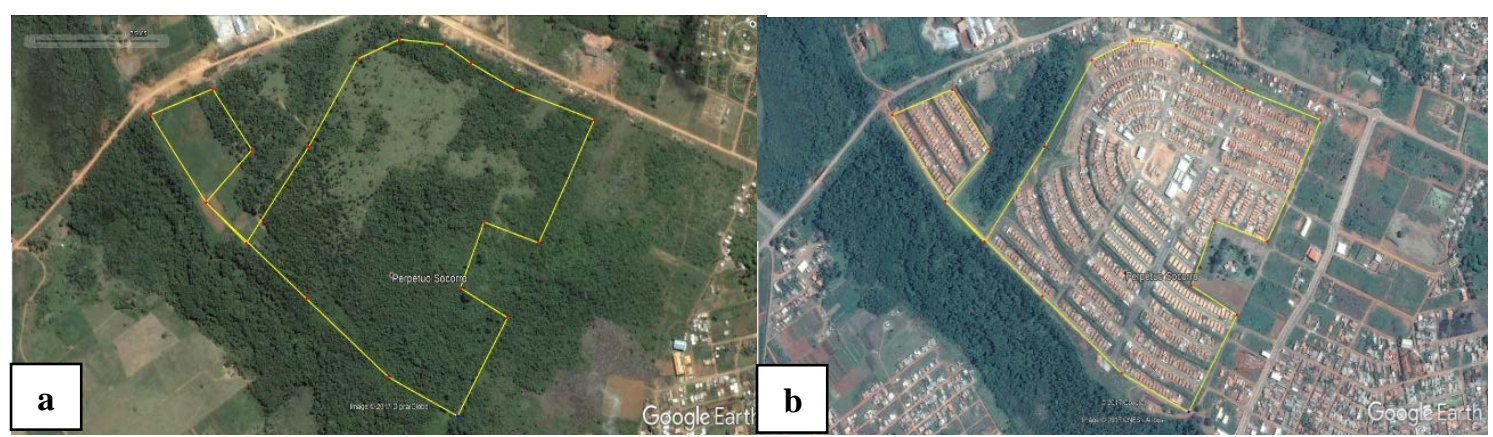

Figura 2. a) Vista superior da área do reassentamento, com a cobertura vegetal e pastagens; b) vista superior da área do reassentamento, sem a cobertura vegetal e com a estrutura civil. Fonte: Google Earth (2005 e 2017). 


\section{Método}

0 método aplicado foi $\mathrm{o}$ hipotético-dedutivo, pois, de acordo com Gil (2008) utilizou-se uma observação cuidadosa acerca do soerguimento da UHE Belo Monte, e as bases científicas já publicadas, as leis ambientais vigentes, para se demonstrar as consequências desse soerguimento.
Quanto à pesquisa, apresenta abordagem quantitativa porque as amostras são grandes e consideradas representativas da população, e qualitativa porque descreve, explica e mostra a relação entre os impactos ambientais e sociais com o soerguimento da UHE Belo Monte (Gerhard e Silveira, 2009). Para melhor aplicá-la, foi dividida em cinco etapas distintas (Figura 3).

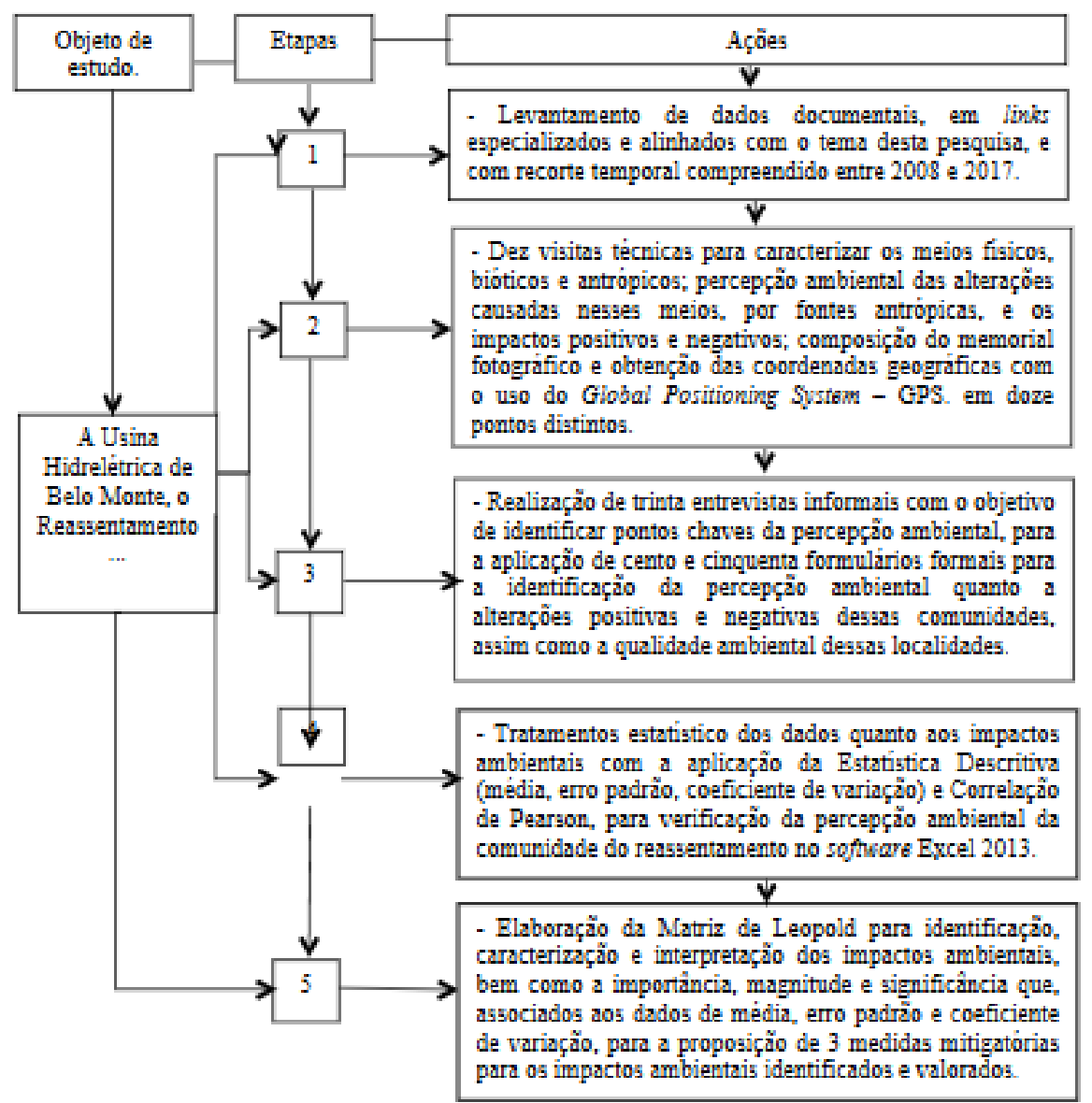

Figura 3. Fluxogramas das etapas metodológicas aplicadas a esta pesquisa. Fonte: autores (2017).

0 RUC São Joaquim reassentou um total de 829 famílias o que corresponde a 3.260 moradores remanejados (Norte Energia, 2015). Foram entrevistadas 150 famílias, que representam aproximadamente $18 \%$ do total $(n)$, o que atende as exigências da estatística descritiva que aceita o mínimo de $10 \%$ do total do Universo da População (N).

\section{Leopold}

Elaboração de uma Matriz de

A Matriz 1 refere-se ao Reassentamento São Joaquim antes e após a conclusão das estruturas 
arquitetônicas com a população reassentada. 0 preenchimento da mesma foi orientado pelas observações realizadas em campo, memorial fotográfico e baseado nas respostas obtidas nos formulários. Os conceitos e critérios utilizados nas matrizes (Tabela 1) obedecem aos padrões usados nessa área de pesquisa.

Tabela 1. Descrição dos critérios de importância e dos valores aplicados nessa pesquisa aos impactos identificados na área de estudo (Altamira-PA).

\begin{tabular}{|c|c|c|}
\hline Critérios de classificação & Impacto & Descrição \\
\hline \multirow{2}{*}{ Expressão } & Positivo (1) & $\begin{array}{l}\text { Quando um impacto causa benefícios } \\
\text { meio ambiente. }\end{array}$ \\
\hline & Negativo $(-1)$ & $\begin{array}{l}\text { Quando um impacto causa malefícios ao } \\
\text { meio ambiente. }\end{array}$ \\
\hline \multirow{2}{*}{ Ordem } & Direto (2) & $\begin{array}{l}\text { Quando resulta de uma ação de causa e } \\
\text { efeito. }\end{array}$ \\
\hline & Indireto (1) & $\begin{array}{l}\text { Quando é uma reação secundária em } \\
\text { relação à ação supracitada. }\end{array}$ \\
\hline \multirow{2}{*}{ Duração } & Permanente (2) & $\begin{array}{l}\text { Executada a ação, os impactos não param } \\
\text { de se manifestar. }\end{array}$ \\
\hline & Temporário (1) & $\begin{array}{l}\text { Quando o impacto ambiental permanece } \\
\text { por um tempo determinado. }\end{array}$ \\
\hline \multirow{2}{*}{ Escala temporal } & Imediato (2) & $\begin{array}{l}\text { São aqueles que ocorrem } \\
\text { simultaneamente à ação que o gera. }\end{array}$ \\
\hline & $\begin{array}{l}\text { Médio ou Longo } \\
\text { Prazo (1) }\end{array}$ & $\begin{array}{l}\text { São os que ocorrem com certa defasagem } \\
\text { em relação à ação que os geram. }\end{array}$ \\
\hline \multirow[b]{2}{*}{ Reversibilidade } & Irreversível (2) & $\begin{array}{l}\text { Quando cessada a ação, o meio ambiente } \\
\text { não retorna às suas condições originais. }\end{array}$ \\
\hline & Reversível (1) & $\begin{array}{l}\text { Após cessada a ação, o meio ambiente } \\
\text { retorna às condições originais de } \\
\text { maneira natural ou por ação humana. }\end{array}$ \\
\hline \multirow[t]{2}{*}{ Cumulatividade } & Cumulativos (2) & $\begin{array}{l}\text { São aqueles que se acumulam no tempo e } \\
\text { no espaço. }\end{array}$ \\
\hline & Não Cumulativos (1) & Não se acumulam no tempo e no espaço. \\
\hline \multirow{2}{*}{ Escala espacial } & Regional (2) & $\begin{array}{l}\text { Quando o impacto se propaga por uma } \\
\text { área além das imediações do projeto. }\end{array}$ \\
\hline & Local (1) & $\begin{array}{l}\text { Quando o impacto localiza- se na área do } \\
\text { projeto. }\end{array}$ \\
\hline
\end{tabular}

Fontes: Amorim (2011) e Kaercher et al. (2013).

O cálculo para significância foi adaptado de Amorim (2011).
Para a sua efetivação, aplicou-se a Equação 1.

$$
\text { Significância }=E \cdot\left(\sum O+D+E T+R+C+E E\right)
$$


Onde:

$\mathrm{E}=$ Expressão;

$\mathrm{O}=$ Ordem;

$\mathrm{D}=$ Duração;

ET = Escala Temporal;

$\mathrm{R}=$ Reversibilidade;

$\mathrm{C}=$ Cumulatividade;

$\mathrm{EE}=$ Escala Espacial

Em seguida, ao valor obtido (significância), foi aplicado um critério qualitativo, de pequeno, médio ou grande impacto. Esta quantiqualificação é baseada nos valores máximos e mínimos que podem ser atingidos para cada impacto, conforme os valores estabelecidos para cada critério (Tabela
1), que foram baseados nos valores estabelecidos por Sánchez (2013) e da qualificação preconizada pela Food and Agriculture Organization of The Unites Nations para o Estudo de Impactos Ambientais (FAO, 2011, p. 17), complementado com o que preconizaram Amorim (2011) e Kaercher (2013).

Tabela 1. Classificação da significância dos impactos positivos e negativos.

\begin{tabular}{|c|c|c|c|c|c|c|c|c|c|c|c|c|c|c|}
\hline & & & & & & & gnif & $\hat{\text { ânc }}$ & & & & & & \\
\hline & \multicolumn{7}{|c|}{ Positiva } & \multicolumn{7}{|c|}{ Negativa } \\
\hline \multirow{2}{*}{ Classificação } & 6 & 7 & 8 & 9 & 10 & 11 & 12 & -6 & -7 & -8 & -9 & -10 & -11 & -12 \\
\hline & \multicolumn{2}{|c|}{$P$} & \multicolumn{3}{|c|}{$M$} & $\mathrm{G}$ & & \multicolumn{2}{|c|}{$\mathrm{P}$} & \multicolumn{2}{|c|}{ M } & \multicolumn{3}{|c|}{$G$} \\
\hline
\end{tabular}

Adaptado de Amorim (2011) e Kaercher (2013).

Posteriormente, os critérios e impactos foram comparados, com utilização do software Microsoft Excel (2013), para o estabelecimento do percentual de impactos por significância.

\section{Resultados e discussão}

\section{Quanto ao grau de escolaridade}

A análise dos dados obtidos para esse item indicou que 68 indivíduos amostrados (45,3\%), possuem o ensino fundamental incompleto, e que há 26 $(17,3 \%)$ indivíduos sem letramento (Figura 4).

Estudo efetuado na Vila Parque Santa Anita, Porto Alegre (RS), por
Lermen e Fisher (2010), concluiu que quanto maior a escolaridade, maior a percepção tanto da existência como da gravidade dos problemas ambientais. Em Altamira, os valores para indivíduos amostrados sem letramento $(17,3 \%)$, não os deixa sem uma avaliação qualitativa da percepção ambiental em relação às transformações ocorridas no ambiente onde reside atualmente e onde residia anteriormente. Com base nos indivíduos amostrados sem letramento, acredita-se que a escola existente no reassentamento, venha a suprir essa carência para as atuais e futuras gerações dessas famílias (Figura 5). 


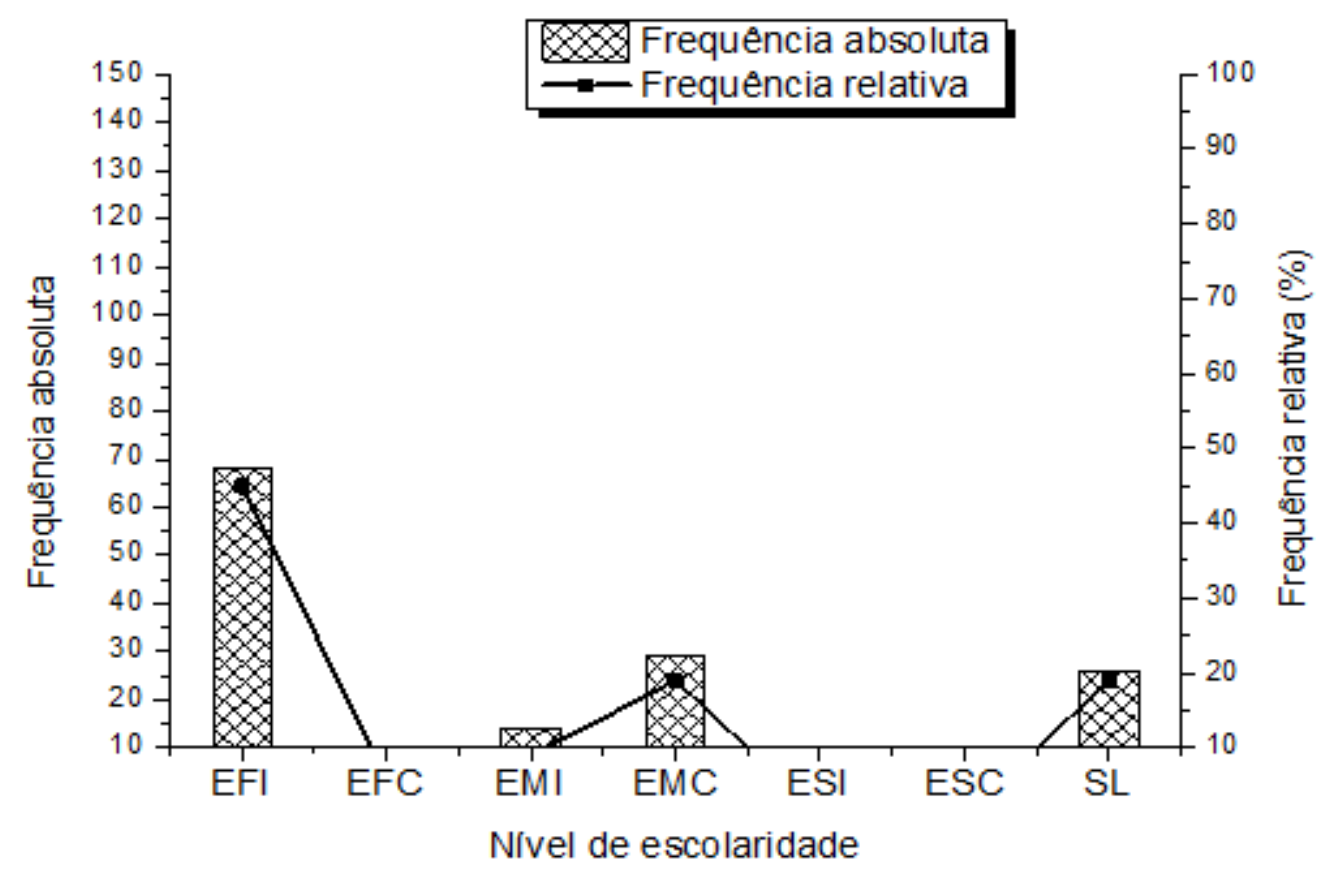

Figura 4. Graus de escolaridade da comunidade do RUC São Joaquim. EFC - Ensino Fundamental Completo; EFI - Ensino Fundamental Incompleto; EMC - Ensino Médio Completo; EMI - Ensino Médio Incompleto; ESC - Ensino Superior Completo; ESI - Ensino Superior Incompleto. Fonte: autores (2017)

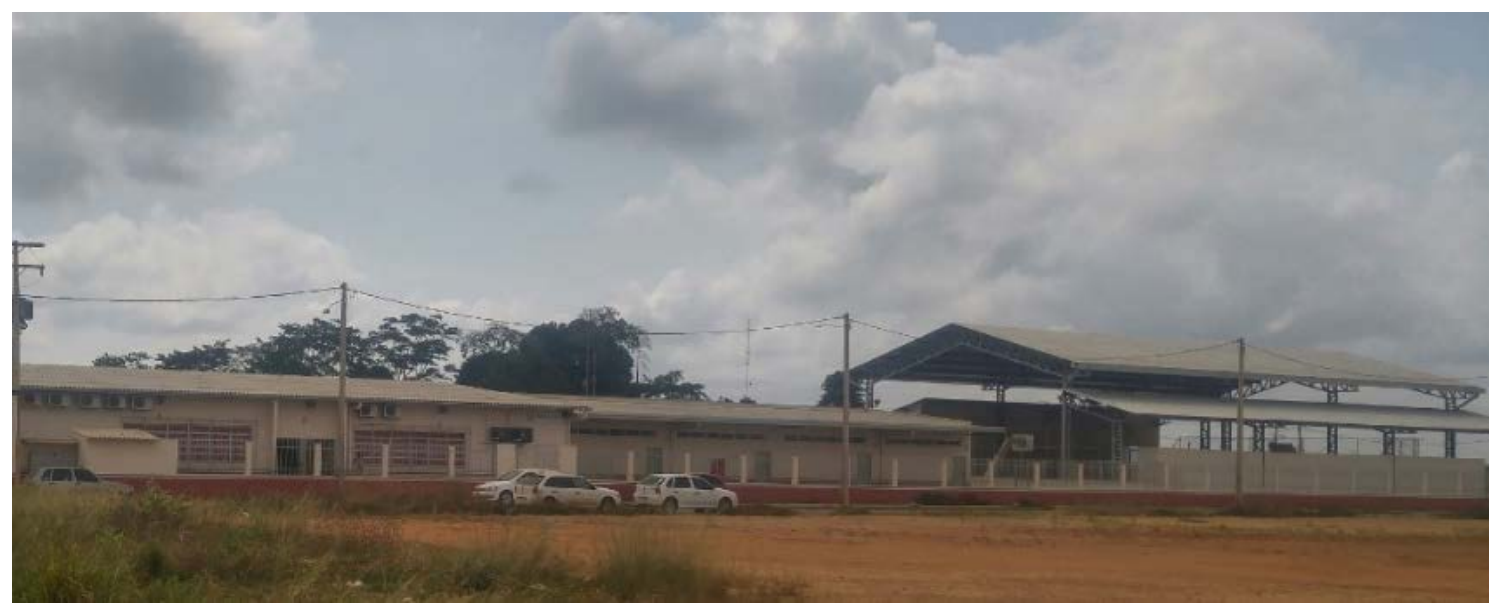

Figura 5. Vista frontal da Escola de Ensino Fundamental no RUC São Joaquim (Altamira-PA). Fonte: autores (2017).

\section{Em função do tempo de residência em Altamira}

Em relação ao tempo de residência no município, os dados obtidos indicaram que, dos 150 indivíduos amostrados, $73 \quad(48,6 \%)$ residem em Altamira a mais de 30 anos, e 6 (4\%), não completaram um ano ou ainda não estão a 5 anos no município (Figura 6). 


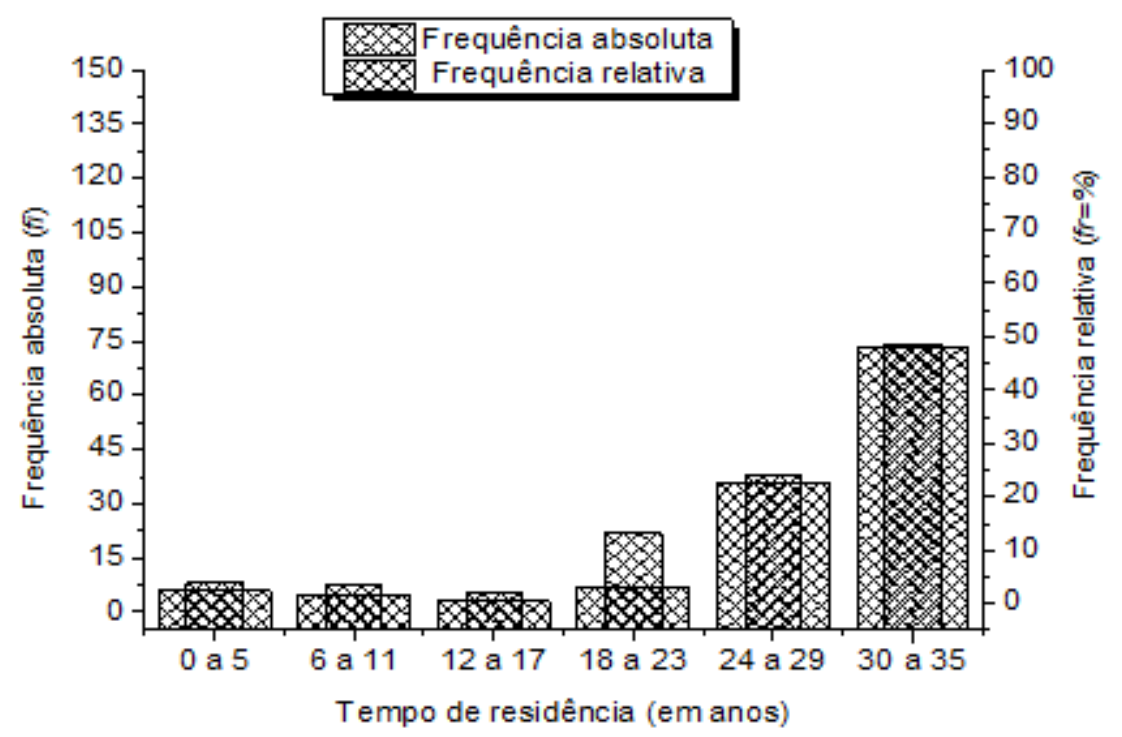

Figura 6. Valores para a frequência absoluta e relativa para o tempo de residência dos indivíduos amostrados. RUC São Joaquim (Altamira-PA). Fonte: autores (2017).

0 maior tempo de residência dos indivíduos amostrados, 73 (48,6\%) já habitam no município a mais de trinta anos, isso contribui para a percepção ambiental mais efetiva em função da mudança ocorrida entre o antigo local de residência e o atual, embora não esteja associado ao grau de estudo. A despeito destes indivíduos amostrados que já residem no município há mais de 30 anos, e que se encontravam em situações diferentes de vulnerabilidade socioeconômica em sua antiga moradia, a mobilidade empregada para o RUC São Joaquim a médio e longo prazo, poderá servir como um mecanismo de redução da vulnerabilidade dos indivíduos que ali se encontram.

De acordo com estudo desenvolvido por Barbieri (2011), a mobilidade é um mecanismo de adaptação das populações mais pobres ou mais vulneráveis e que experiências de desastres naturais como a do Furacão
Mitch na América Central, são indicadores de que as populações mais vulneráveis são aquelas incapazes de mudarem seus locais de residência em risco a um desastre natural, para lugares com menor risco em função de suas condições socioeconômicas. A pesquisa em questão corrobora com os resultados obtidos nas entrevistas com os moradores do RUC São Joaquim, onde os mesmos afirmaram que moravam em local de risco, sem infraestrutura e saneamento básico.

\section{Quanto à transformação na vida dos remanejados}

No que se refere à transformação na qualidade de vida dos remanejados, a análise dos dados obtidos, indicou que 130 (86,6\%) indivíduos amostrados relataram que esse deslocamento até o RUC São Joaquim, causou transformações positivas como, por exemplo, a infraestrutura ofertada (Figura 7). 


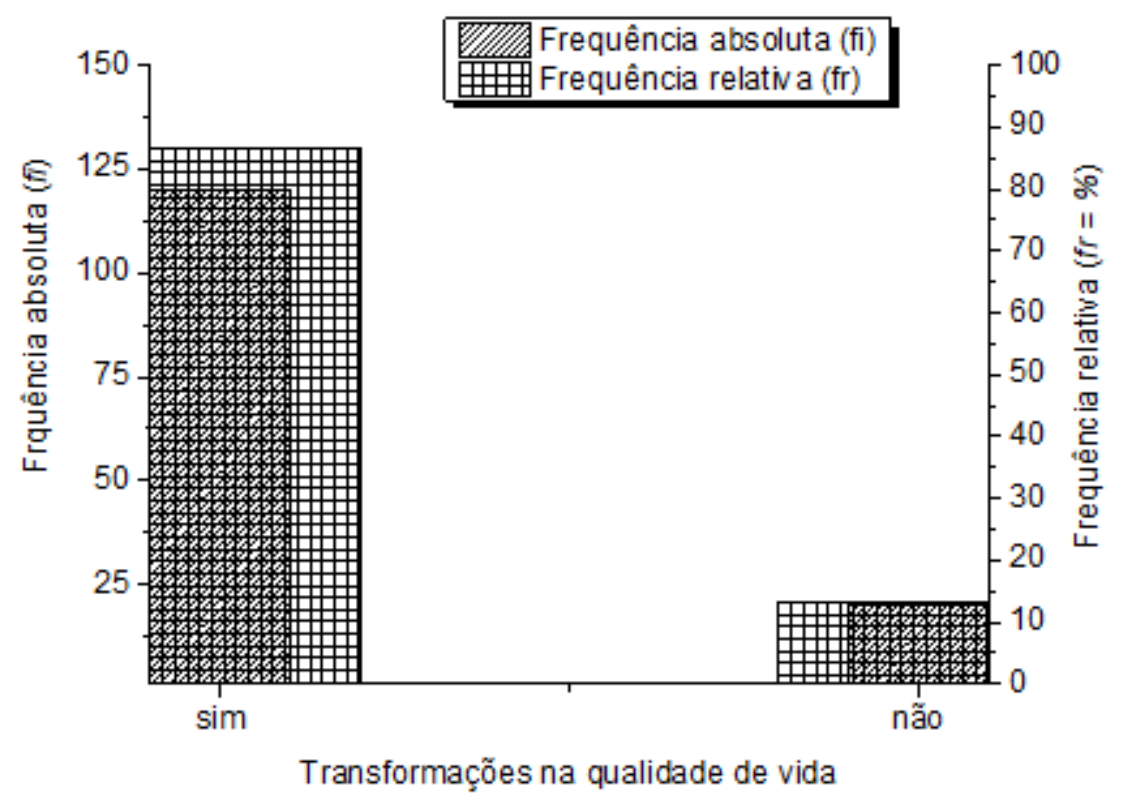

Figura 7. Percepção quanto as transformações ocorridas na qualidade de vida dos indivíduos amostrados. RUS São Joaquim (Altamira-PA). Fonte: autores (2017).

Pesquisa realizada no vale do Jequitinhonha (MG), por Freitas et al. (2013), indicou que a identidade cultural de um povo, com todas as suas peculiaridades, é construída através da interpretação de um mundo que é marcado por signos e símbolos, festas, as músicas, as celebrações religiosas, as comidas, as danças e outras manifestações culturais. Por isso, nas construções das grandes barragens, a inundação e o descolamento forçado de uma determinada população, podem significar perdas irreparáveis do ponto de vista sociocultural, além de carregar consigo processos sociais marcados pela desterritorialização e pela reterritorialização dos atingidos. Tal fato foi observado na pesquisa realizada em Altamira, pois, $130(86,6 \%)$ dos 150 indivíduos amostrados, afirmaram que a mudança para o reassentamento causou transformações em suas vidas, e que elas foram tanto positivas quanto negativas.

\section{Em função dos pontos positivos e negativos do remanejamento}

A análise dos dados obtidos para esse tema, indicou que 148 (98,6\%) indivíduos amostrados consideram a coleta de lixo como ponto positivo, e 56 $(37,3 \%)$, consideram o comércio como um ponto negativo (Figura 8).

Quanto ao comércio representar ponto negativo, a razão está na variedade de produtos básicos (ex.: sabão em pó) cujo preço é elevado, pois, os residentes, na grande maioria, são hipossuficientes econômicos. Os dados obtidos também indicaram que os indivíduos amostrados possuem visões diferentes acerca da percepção ambiental do local onde atualmente residem, pois, o que para a maioria é benéfico, para outros é sinônimo de insatisfação. Em relação a isso, um dos pontos negativos de maior valor, está associado a segurança, pois, $66(44 \%)$ acreditam que esse determina uma queda na qualidade de vida da comunidade. 

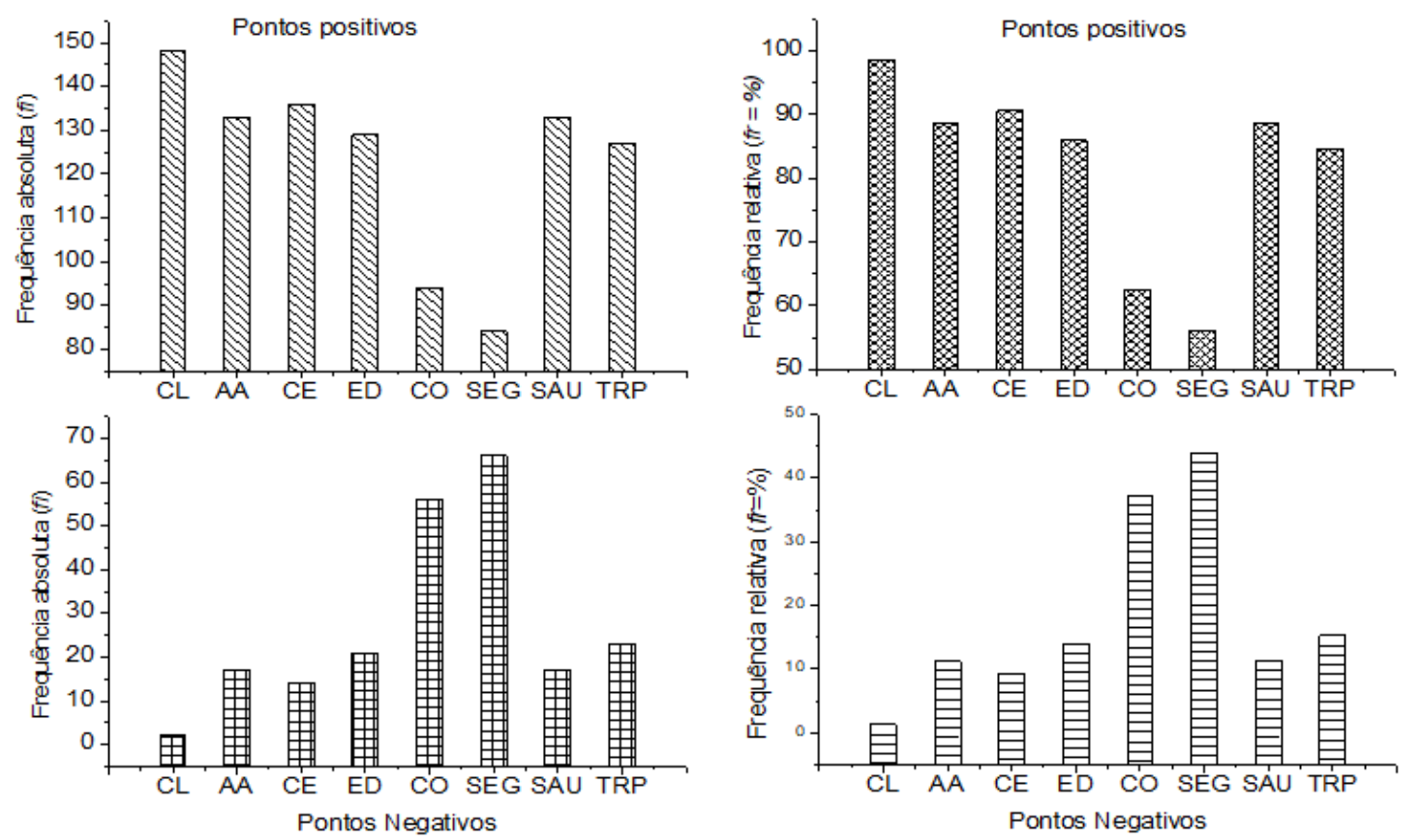

Figura 8. Pontos positivos e negativos identificados pelos 150 indivíduos amostrados. RUC São Joaquim. (Altamira-PA). CL - Coleta de Lixo; AA - Abastecimento de água; CE - Coleta de Esgoto; ED Educação; CO - Comércio; SEG - Segurança; SAU - Saúde; TRP - Transporte. Fonte: autores (2017).

$\mathrm{Na}$ pesquisa efetuada em Altamira, o saneamento básico foi subdividido em coleta de esgoto, abastecimento de água e coleta de lixo. Neste contexto, os dados obtidos apresentaram padrão positivo, pois 136 $(90,6 \%)$ dos indivíduos amostrados consideram o saneamento básico (somatória das três ações), como ponto positivo no RUC São Joaquim. Ao contrário do estudo realizado no Rio de Janeiro (RJ), por Leoneti et al. (2011), que concluiu que o impacto na qualidade de vida, na saúde, educação, trabalho, ambiente, e saneamento básico envolve a atuação de múltiplos agentes em uma ampla rede institucional.

Apesar de 98,6\% dos indivíduos amostrados considerarem a coleta de lixo como um ponto positivo, pode ser verificado que já há disposição inadequada de resíduos no reassentamento por parte dos moradores (Figuras 9a e 9b).

Quanto ao grau de compensação segundo os moradores No que se refere ao índice de compensação em relação à desapropriação para recebimento da nova moradia, os dados obtidos indicaram que $113 \quad(75,3 \%)$ dos entrevistados, consideram que seu remanejamento foi, de fato, compensatório porque os indivíduos amostrados relataram que houve melhoras quanto à área de risco, infraestrutura e saneamento ofertado no RUC São Joaquim, quando comparado ao local onde residiam, e 37 (24,6\%) declararam que não foi compensatório, apontando como principal motivo a distância do centro da cidade (Figura 10). 


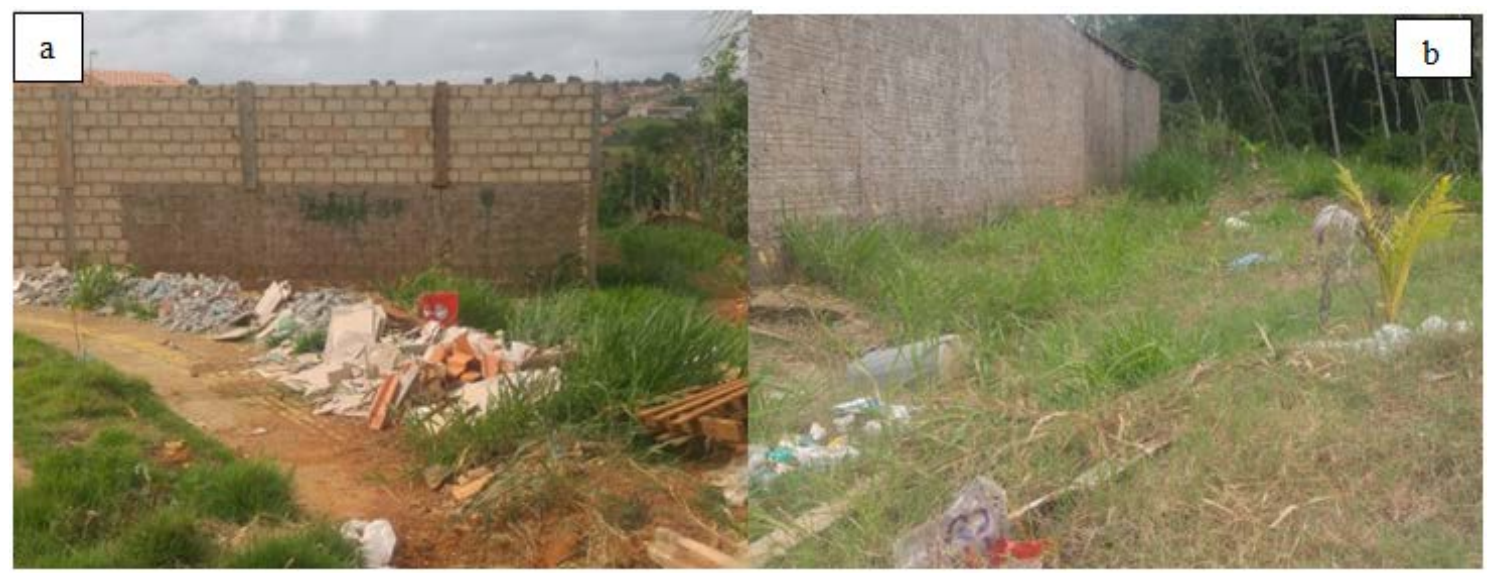

Figura 9. a) Vista lateral de um lote semiurbanizado que é utilizado como depósito de resíduos a céu aberto; b) Vista frontal de outro lote contendo resíduos sólidos. RUC São Joaquim (AltamiraPA). Fonte: autores (2017).

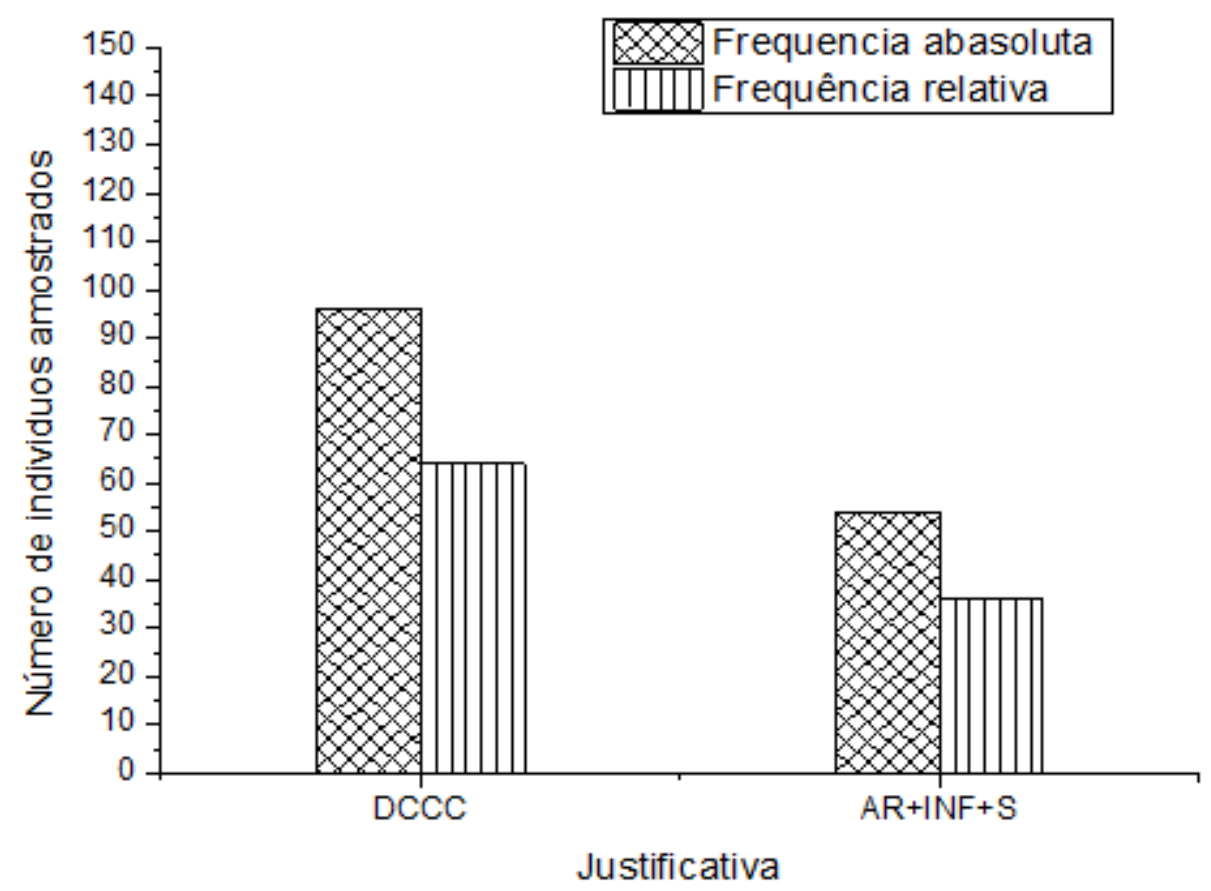

Figura 10. Justificativas citadas pelos indivíduos amostrados no sentido de melhorias em relação a área onde anteriormente habitavam e o RCU São Joaquim (Altamira-PA). Legendas: DCC: Distância do centro da cidade; AR: Área de risco; I: infraestrutura; S: saneamento. Fonte: autores (2017).

Em um estudo efetuado no Rio de Janeiro (RJ), Oliveira e Conceição (2016), esses autores concluíram que é imprescindível que se faça uma discussão sobre como a materialização de políticas compensatórias a qual estabelece relações sociais e intervenções territoriais com potencial de produção de novos impactos negativos, o que, em contrapartida, exigiria a disponibilização de monitoramento continuado dos locais, sujeitos e políticas a fim de compreender e, concomitantemente, corrigir os liames das condicionantes socioambientais que 
promovam a violação de direitos humanos. De acordo com os resultados obtidos na pesquisa no reassentamento São Joaquim, as ações quanto ao monitoramento continuado das condicionantes impostas são ativas, uma vez que a maioria dos entrevistados declararam que foi compensatório a perda da antiga moradia para o recebimento da moradia atual.

\section{Em relação à avaliação da infraestrutura no RUC São Joaquim}

As análises dos dados obtidos para esse tema indicaram que 47 indivíduos amostrados (47,3\%), consideram a infraestrutura no RUC boa, mas um $(0,66 \%)$, dos 150 desses indivíduos, considera a infraestrutura ofertada no RUC, péssima, quando comparada com aquela existente no local anterior (Figura 11).

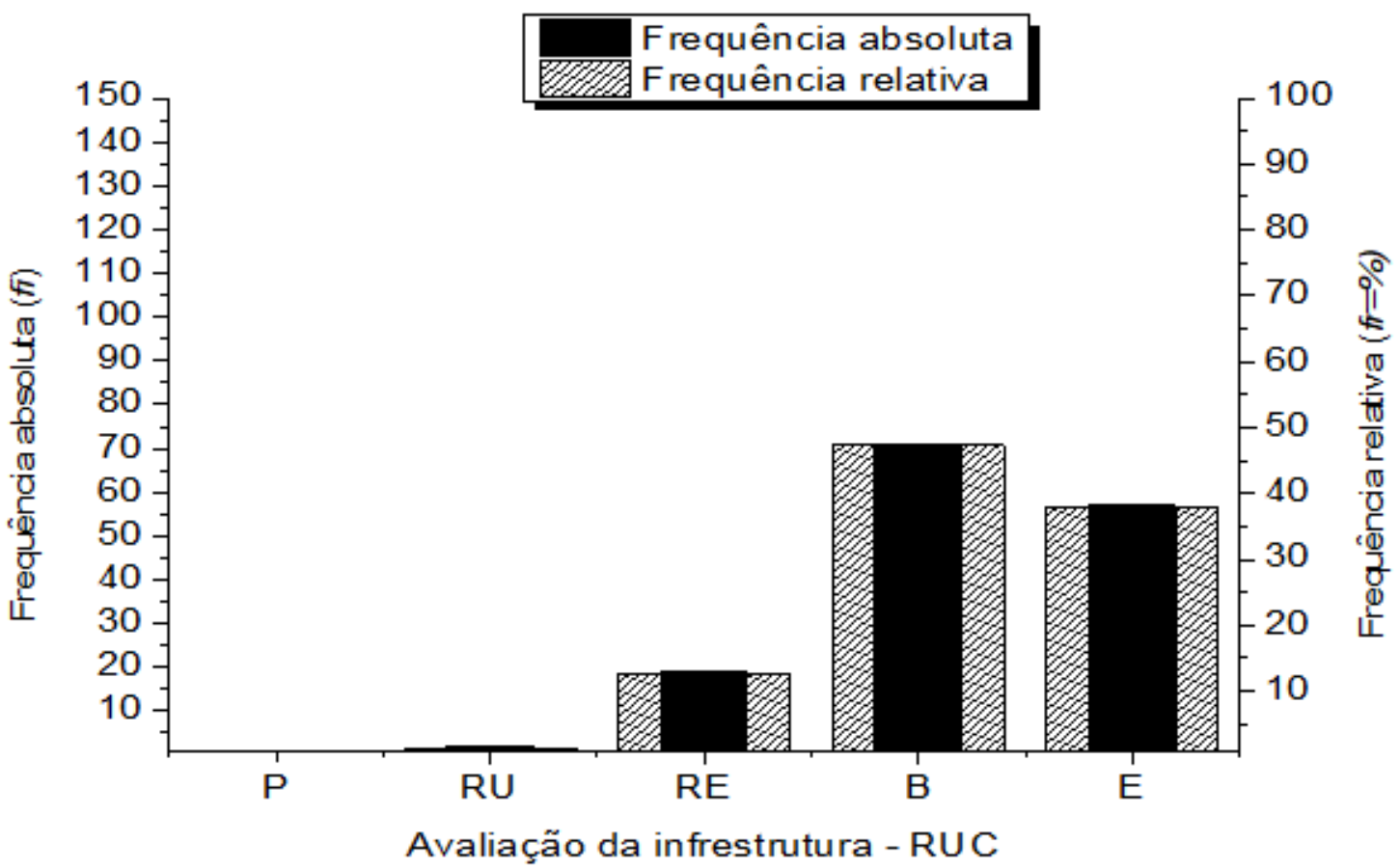

Figura 11. Valores obtidos na amostragem realizada junto aos indivíduos amostrados quanto a infraestrutura existente no RUC São Joaquim e aquela anterior (Altamira-PA). Legendas: P: Péssima; RU: Ruim; RE: Regular; B: Boa; E: Excelente. Fonte: autores (2017).

Em pesquisa realizada em Marrakech, por Carmo (2009), indicou que um dos impactos oriundos do processo de urbanização consiste na reemergência da epidemia de dengue, relacionada à falta de serviços de infraestrutura básica, como água canalizada, esgoto e coleta de lixo. $\mathrm{Na}$ pesquisa efetuada no RUC São Joaquim, não houve relato sobre tal epidemia, 0 que se contrapõe ao resultado obtido em Marrakech. Isso está associado a infraestrutura ofertada no reassentamento, como o sistema de drenagem, unidade de saúde (Figura 12) e da contribuição da comunidade que deve praticar ações para evitar a disseminação do vetor Aedes aegypti. 


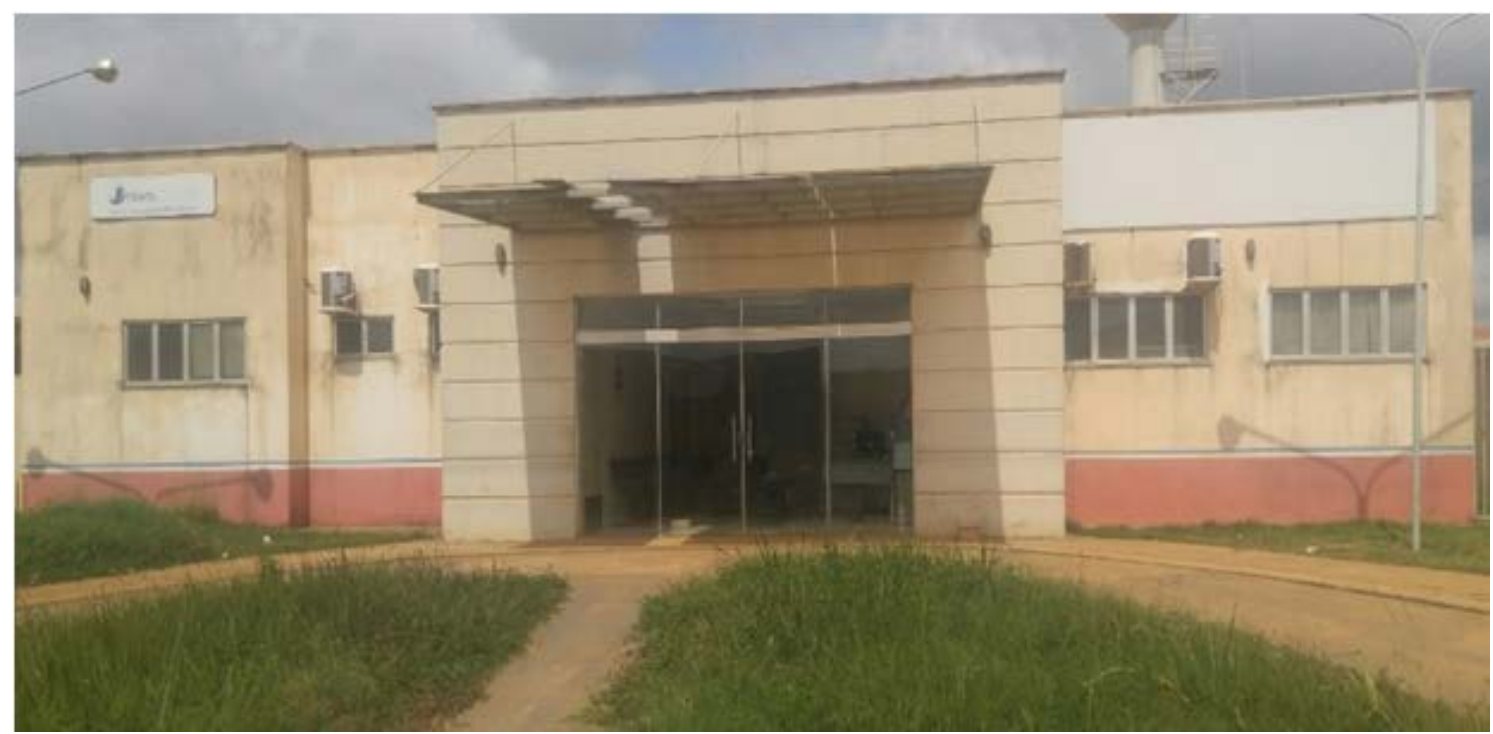

Figura 12. Vista frontal da Unidade de Saúde localizada no RUC São Joaquim (Altamira-PA). Fonte: autores (2017)

\section{Quanto à comparação entre as unidades arquitetônicas residências (antiga e atual) \\ Os dados obtidos e analisados indicaram que 96 (64\%) dos indivíduos}

amostrados preferem a moradia atual, enquanto que $54 \quad(36 \%)$ dos entrevistados preferem a então antiga moradia (Figura 13).

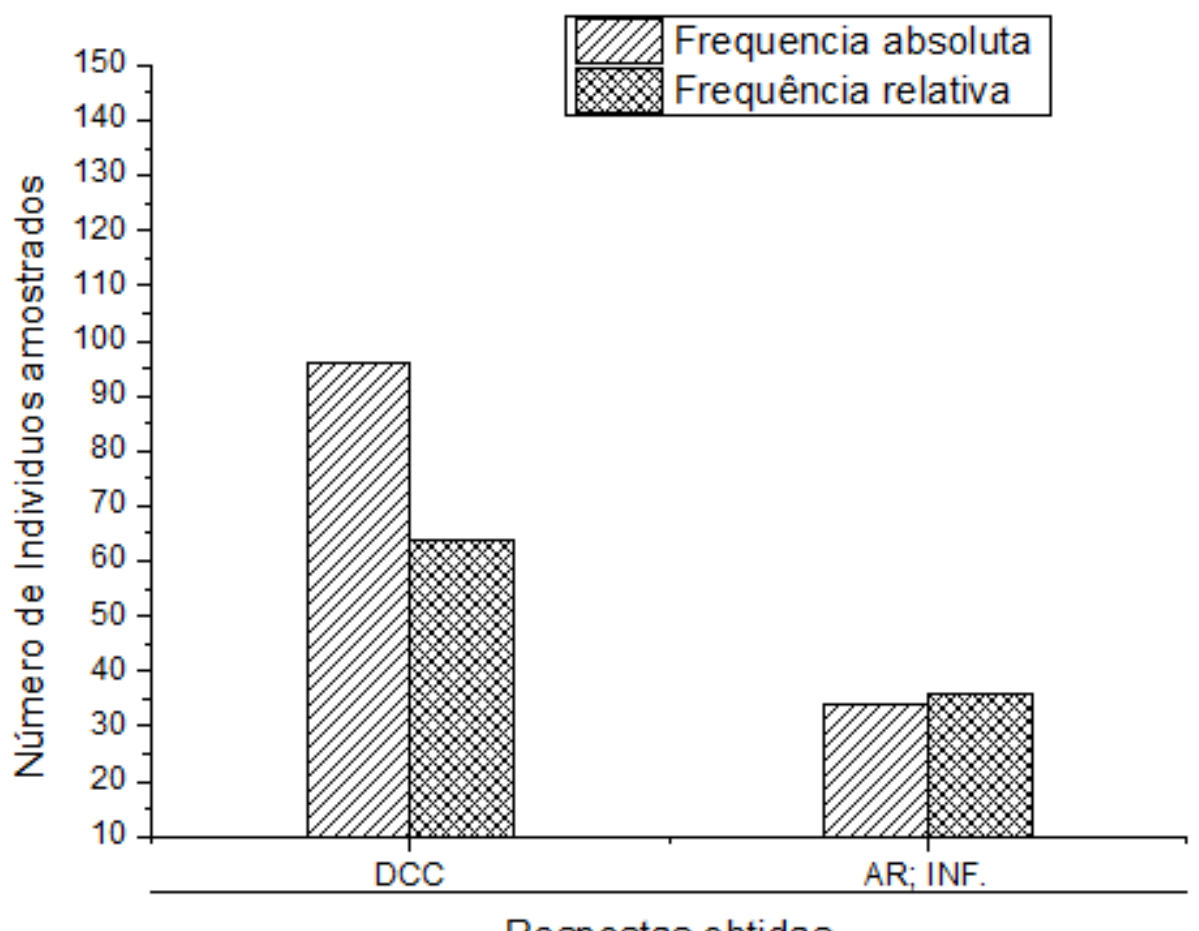

Respostas obtidas

Figura 13. As quatro justificativas para preferir a Unidade Arquitetônica Anterior e a atual. RUC São Joaquim (Altamira-PA). Legendas: DCC: Distância do Centro da Cidade; C: do Comércio; AR: Área de Risco; Infraestrutura. Fonte: autores (2017). 
No estudo efetuado em Salvador (BA), Campos et al. (2013) concluíram que os moradores de um complexo residencial do Programa Minha Casa Minha Vida, do Governo Federal, mostraram-se satisfeitos com a moradia, e afirmam que não gostariam de voltar para a antiga moradia, pela maior qualidade do apartamento com relação a ela. Em Altamira, os dados indicaram que a maioria dos participantes considera sua moradia atual um lar (Figura 14a) e foi associado ao fato da propriedade dessa casa nova, com infraestrutura superior ao local anterior (Figura14b), e isso contribui para uma melhora na percepção ambiental desses moradores.

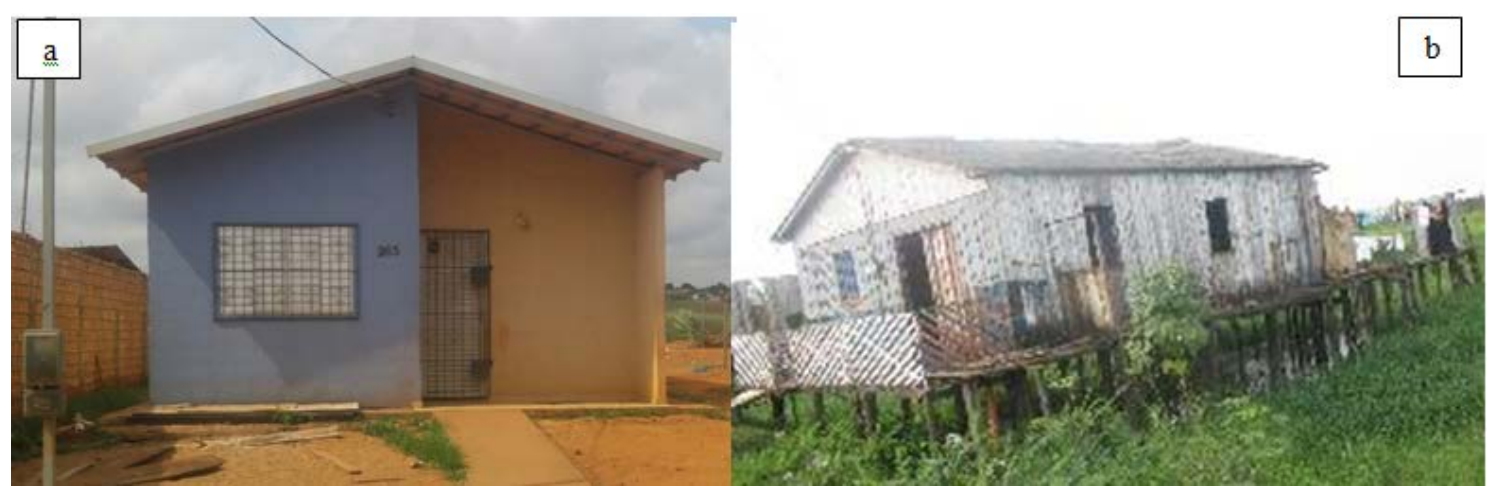

Figura 14. a) Vista frontal da estrutura arquitetônica existente no RUC São Joaquim; b) Vista frontolateral da estrutura arquitetônica onde residiam os remanejados (Altamira-PA). Fonte: autores (2017).

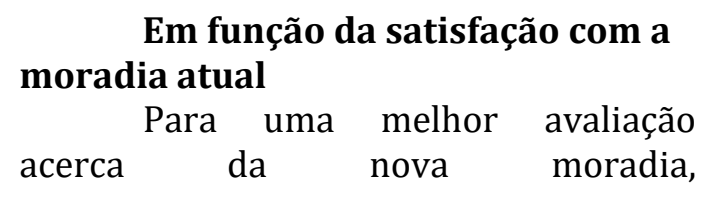

os 150 indivíduos amostrados,
atribuíram cinco critérios à essa
avaliação (Figura 15).

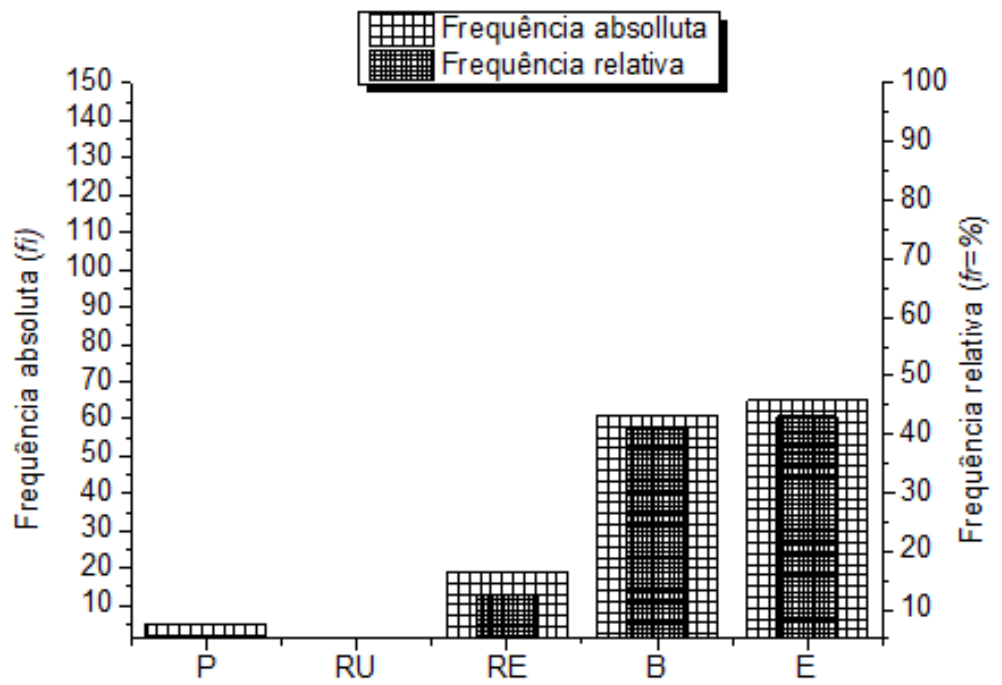

Cinco critérios qualitativos atribuidos à nova moradia

Figura 15. As cinco qualidades identificadas para a nova moradia, de acordo com 150 indivíduos amostrados. RUC São Joaquim (Altamira-PA). Legendas: P: Péssimo; RU: Ruim; RE: Regular; B: Bom; E: Excelente. Fonte: autores (2017). 
A análise dos dados obtidos para esse item indicou que $65 \quad(43,3 \%)$ indivíduos amostrados estão satisfeitos, e $5(3,3 \%)$ não estão satisfeitos, e atribuíram o critério "péssimo" à nova moradia. A soma da quantidade de indivíduos amostrados cuja satisfação encontra-se entre boa e excelente $(126=$ $86,9 \%$ ), indicaram que a percepção ambiental se elevou e isso está relacionado com a infraestrutura física ofertada e a disposição dessa comunidade.

Pesquisa realizada em
Ananindeua (PA), por Costa et al. (2016), indicou que a avaliação e adaptação dos moradores quanto ao remanejamento e reassentamento habitacional obteve um número significativo de moradores que informaram estarem satisfeitos com aspectos relacionados ao saneamento, os serviços urbanos, a educação, saúde, lazer (Figura 16a e 16b) e segurança presente nas novas moradias e quase inexistente nas moradias anteriores. $\mathrm{Na}$ pesquisa realizada em Altamira, os indivíduos amostrados qualificaram esses serviços como bom e excelente, 0 que comprova que a infraestrutura ofertada melhorou a qualidade de vida desta comunidade.

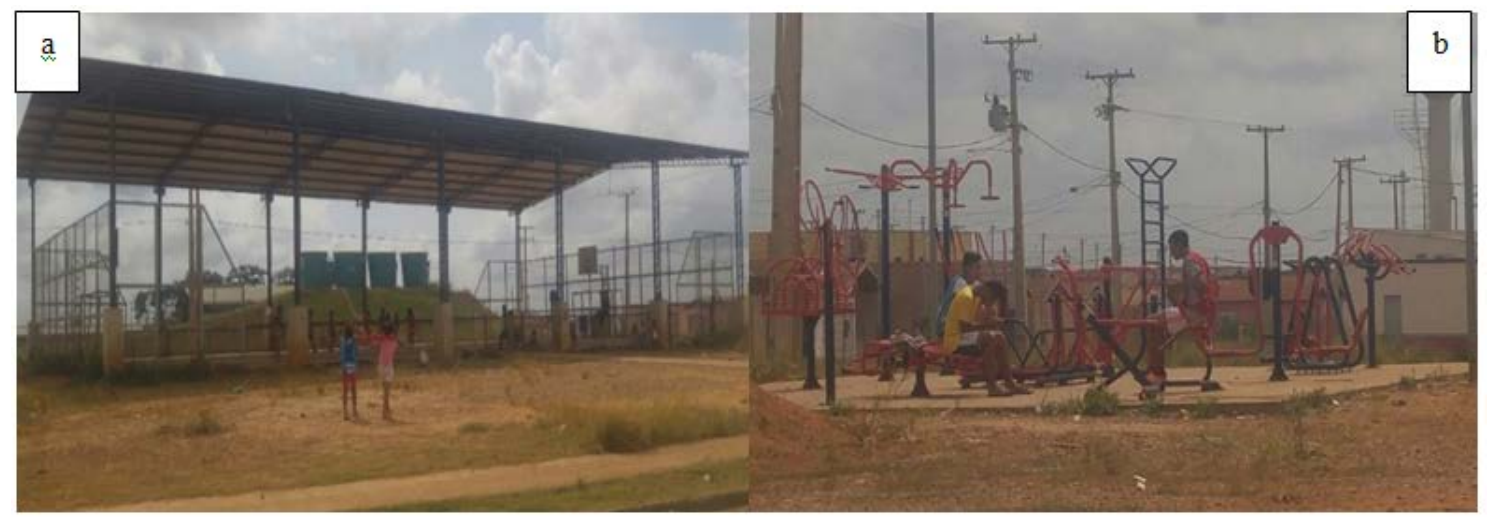

Figura 16. Vistas frontais: a) da quadra esportiva; b) da academia ao ar livre. RUC São Joaquim (Altamira-PA). Fonte: autores (2017)

Ademais, as análises dos dados obtidos indicaram que 113 (75,3\%) dos indivíduos amostrados, consideram o remanejamento para o RUC São Joaquim, foi compensatório em função da área de risco em que residiam, a falta de infraestrutura e saneamento. Porém, 37 $(24,6 \%)$ demonstram-se insatisfeitos, e estes, tem como justificativa a distância do centro da cidade e o perigo.

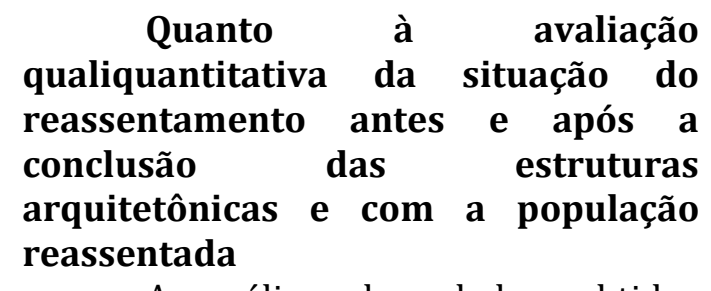

A análise dos dados obtidos indicou a ocorrência de 26 impactos dispersos no reassentamento como um todo (Matriz 1). 
Matriz 1. Principais impactos ambientais ocorridos no RUC São Joaquim. Altamira/PA.

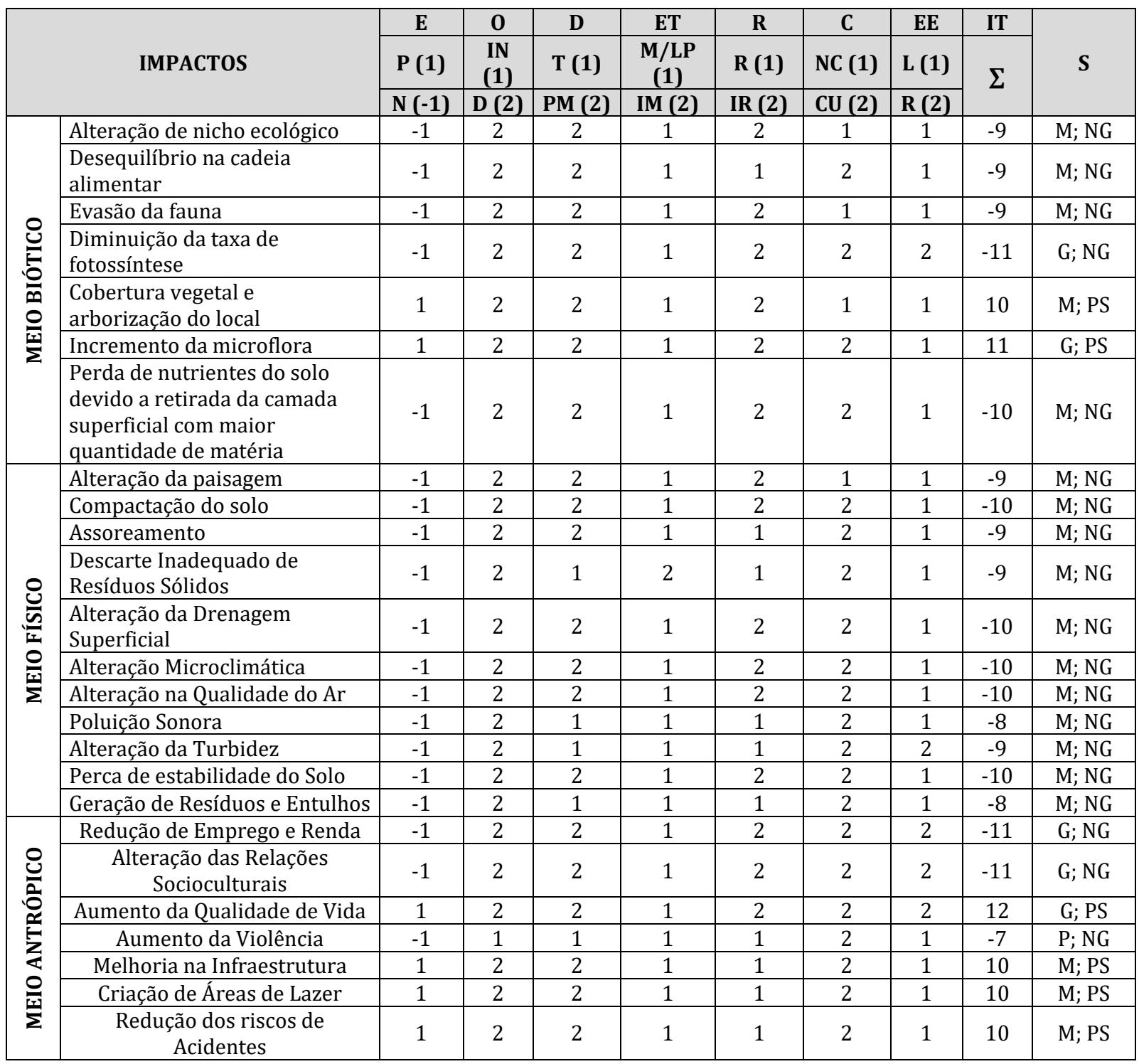

Legendas: $\mathbf{E}=$ Expressão ( $\mathbf{P}=$ Positivo; $\mathbf{N}=$ Negativo); $\mathbf{O}=$ Ordem $(\mathbf{D}=$ Direto; $\mathbf{I N}=$ Indireto) $\mathrm{D}=$ Duração ( $\mathbf{T}=$ Temporário; $\mathbf{P M =}$ Permanente); $\mathbf{E T}=$ Escala Temporal (IM= Imediato; $\mathbf{M} / \mathbf{L P}=\mathbf{M e ́ d i o}$ ou Longo Prazo); $\mathbf{R}=$ Reversibilidade (IR= Irreversível; $\mathbf{R}=$ Reversível); $\mathbf{C}=$ Cumulatividade (CU= Cumulativo; NC= Não Cumulativo); $\mathbf{E E}=$ Escala Espacial (L= Local; $\mathbf{R}=$ Regional); $\mathbf{I} \mathbf{T}=$ Impacto Total; $\mathbf{S}=$ Significância ( $\mathbf{P Q}=$ Pequena; $\mathbf{M}=$ Média; $\mathbf{G}=$ Grande; $\mathbf{P S}=$ Positiva; $\mathbf{N G}=$ Negativa).

Fonte: autores (2017).

Os dados obtidos e analisados para os três meios ambientais (biótico, físico, antrópico/socioeconômico) indicaram a existência de 25 impactos (19 de origem negativa e 6 de origem positiva). Em estudo realizado em Vales do Jequitinhonha e Mucuri (MG), Bedoya et al. (2016) concluíram que os impactos gerados nas grandes barragens provocam conflitos nas comunidades localizadas nas zonas de influência e construção dos projetos, impactos negativos principalmente sobre o meio ambiente, subsistência, saúde, relações sociais, impactos que devem ser avaliados adequadamente para a mitigação das consequências que afrontam a população atingida pelo desenvolvimento do projeto. 
Para o MEIO BIÓTIC0, a análise dos dados indicou um valor médio para os impactos negativos $(\mathrm{V}=-9,6 ; \mathrm{S}$ : Média). A análise também indicou que, três variáveis (alteração do nicho ecológico, desequilíbrio na cadeia alimentar e evasão da fauna) com valor igual a $(V=-9)$, ratificam a especificação da significância empregada. Portanto, conclui-se que há uma relação de causaefeito entre os três impactos, pois com a alteração do nicho ecológico há a evasão da fauna, consequentemente causando um desequilíbrio na cadeia alimentar, e perda de biodiversidade.

Pesquisa efetuada em Uberlândia (MG), por Oliveira et al. (2008), indicou que existe uma constante troca de energia e matéria entre o meio biológico e o meio abiótico, qualquer alteração em uma dessas partes provoca um desequilíbrio em cadeia. Essa pesquisa corrobora com os resultados negativos obtidos no Meio Biótico, pois a natureza dos impactos e os valores obtidos levam a isso. Pela análise dos dados obtidos em Altamira, isso está em evidência.

Em relação ao incremento da microflora (V = 11; S: Grande), a análise dos resultados indicou que esse foi $o$ único impacto de grande significância no meio biótico, o mesmo representa caráter positivo, resultante da cobertura vegetal e arborização realizada na área de estudo.

Os dados obtidos para o MEIO FísIC0, indicaram que todos os impactos identificados são negativos (Ex.: compactação do solo, alteração da drenagem superficial, alteração na qualidade do ar, descarte inadequado de resíduos sólidos). Por isso a significância negativa $(V=-9,27 ; S$ : Média). Quanto à relação causa $\mathrm{x}$ efeito, eles foram classificados como impactos diretos.

Dois impactos do meio físico (poluição sonora e geração de resíduos da construção civil) receberam significância (V = -8; S: Média). Em relação aos resíduos de obras de construção civil, tem origem no descarte inadequado desses entulhos, essas obras são efetuadas pelos próprios residentes e estão ocorrendo por todo o perímetro do RUC São Joaquim. Outro impacto referese à alteração microclimática $(\mathrm{V}=-10$; $\mathrm{S}$ : Média), causado principalmente em razão da supressão da flora que ali se localizava, e a posterior construção da estrutura civil necessária à realocação dos atuais moradores.

Em estudo realizado no Rio de Janeiro (RJ), por Barbosa et al. (2014), foi constatado que, em muitas cidades, o aumento da temperatura é intensificado por projetos urbanos cujas morfologias dificultam ou canalizam a ventilação, aumentam as áreas de absorção e as de reflexão da luz solar. Consequentemente, o microclima local é alterado e o aumento da temperatura é sentido mais intensamente pela população. Análogo a este fato, no reassentamento em questão, houve a alteração microclimática, e o fator de maior contribuição foi a supressão vegetal feita para a edificação das estruturas arquitetônicas.

No MEIO ANTRÓPICO/SOCIOECONÔMICO, a análise dos dados indicou a existência de impactos identificados positivos $(\mathrm{V}=10,5 ; \mathrm{S}$ : Média), como por exemplo melhoras na qualidade de vida devido a infraestrutura ofertada, e negativos (V = -9,6; S: Média), aqui, a diminuição do emprego e renda (devido à perda do negócio próprio que possuíam e pelo qual não foram indenizados) foi um dos impactos de maior expressão ( $\mathrm{V}=-11$; S: Grande). Outros impactos negativos referem-se ao aumento da violência $(\mathrm{V}=-7 ; \mathrm{S}$ : Pequena) e alteração das relações socioculturais (V = -11; S: Grande). Em estudo realizado no Tocantins (T0), por Parente e Miranda (2014), constatou-se que grande parte da população que morava às margens do Rio Tocantins, onde foi construída a Usina Luís Eduardo Magalhães, perderam muito (Ex.: cultura; tradições, etc.) com a transferência para outros locais de moradia. A pesquisa em questão corrobora com os resultados obtidos nas entrevistas com os moradores do RUC São Joaquim, em que 
afirmaram já estarem habituados com seus costumes e estilos de vida no antigo local de moradia, desses entrevistados $130 \quad(86,6 \%)$ declararam que tal mudança causou transformação em suas vidas.

\section{Proposição \\ de \\ medidas mitigatórias}

Para uma análise qualitativa mais acurada, quanto à percepção ambiental

Tabela 2. Valores para média $\overline{(X)}$, Erro padrão (EP) e coeficiente de variação (CV) de três questões envolvidas com a proposição das medidas mitigatórias (Altamira-PA).

\begin{tabular}{lccc}
\hline Questões analisadas & $\overline{\boldsymbol{X}}$ & $\mathbf{E P}$ & $\mathbf{C V}(\mathbf{\% )})$ \\
\hline Transformação na qualidade de vida & 75 & 0,21 & 3.5 \\
Infraestrutura no RUC São Joaquim & 30 & 0,34 & 13,9 \\
Satisfação com a nova residência & 30 & 0,15 & 33,0 \\
\hline
\end{tabular}

Fonte: autores (2017).

das modificações causadas na vida dos indivíduos amostrados, infraestrutura no RUC e a satisfação com a residência atual, analisaram-se os valores obtidos para a média, desvio padrão e coeficiente de variação (Tabela 2) das respostas obtidas, com a finalidade de proposição de três medidas mitigatórias aos impactos causados.

Ademais, a primeira variável escolhida foi diminuição da taxa de fotossíntese devido ao impacto direto causado pela supressão da vegetação antes da construção da estrutura civil e, que influencia diretamente na cadeia alimentar pela diminuição da capacidade de captar energia e a possibilidade de produzir matéria orgânica. Na segunda variável, disposição inadequada de resíduos sólidos no reassentamento, a taxa de 98,6\% dos indivíduos amostrados que demonstraram estarem satisfeitos com a coleta de lixo, foi um fator determinante para a escolha dessa variável, pois, de forma contraditória com as visitas realizadas, pôde-se identificar que há disposição inadequada de resíduos sólidos em diversos perímetros do reassentamento. Por fim, a segurança, última variável escolhida, um dos pontos de maior valor, foi selecionada devido estar associada a esse item os 66 (44\%) dos indivíduos amostrados que acreditaram que esse seja um fator determinante na queda da qualidade de vida da comunidade.

A análise dos dados obtidos para EP o CV, indicou que há uma homogeneidade nas respostas obtidas, logo, com base nessa análise e nos resultados obtidos na matriz, propõe-se três medidas mitigatórias (Quadro 2).

\section{Conclusão}

Os impactos causados estão presentes nos três meios que compõem o ambiente do reassentamento e a percepção ambiental da comunidade é baixa porque através do estudo pode-se identificar mais alterações negativas do que positivas, embora a qualidade ambiental para a maioria deles seja satisfatória quando comparada com a moradia antiga.

Todavia, os impactos ambientais e socioeconômicos ainda persistem no RUC São Joaquim e necessita que sejam aplicadas as medidas mitigadoras propostas, para que os impactos negativos identificados possam ser mitigados a médio e longo prazo, e que a comunidade reassentada possa ter uma melhor qualidade de vida. Em vista disto, é necessária uma avaliação contínua, visando reduzir os impactos ambientais de caráter negativo promovendo assim, aqueles que são positivos. 
Quadro 2. Identificação dos impactos negativos e proposição de medidas mitigatórias.

\begin{tabular}{|c|c|c|c|}
\hline N. & Proposição & Tipo & Sugestão \\
\hline 1 & $\begin{array}{l}\text { Diminuição da taxa } \\
\text { de fotossíntese. }\end{array}$ & Mitigatória & $\begin{array}{l}\text { Criação de áreas verdes com, no mínimo } 12 \mathrm{~m}^{2} \text {, com } \\
\text { gramíneas e espécies lenhosas de crescimento rápido e } \\
\text { heliófilas. De preferências com espécies endêmicas (Ex.: } \\
\text { Tradescantia fluminenses). } 0 \text { monitoramento poderá ser } \\
\text { efetuado pela comunidade que deve ser submetida a } \\
\text { capacitação quanto ao crescimento e irrigação da espécie } \\
\text { vegetal até a fase adulta. }\end{array}$ \\
\hline 2 & $\begin{array}{l}\text { Disposição } \\
\text { inadequada de } \\
\text { resíduos sólidos no } \\
\text { reassentamento }\end{array}$ & Mitigatória & $\begin{array}{l}\text { Implantar um programa de educação ambiental voltada } \\
\text { para a conscientização da população residente no } \\
\text { reassentamento e intensificar as ações de fiscalização } \\
\text { ambiental por meio do órgão competente. }\end{array}$ \\
\hline 3 & A segurança & Mitigatória & $\begin{array}{l}\text { Criação e implementação de políticas públicas voltadas } \\
\text { para a diminuição da criminalidade e rondas de } \\
\text { patrulhamento policial frequente no bairro. }\end{array}$ \\
\hline
\end{tabular}

Fonte: autores (2017).

Sendo assim, é importante a conscientização de que todas as ações humanas gerarão modificações no sistema ambiental, sendo adversas ou benéficas. Consequentemente, a qualidade de vida dependerá da proteção do meio ambiente físico e biológico por meio de ações efetivas, éticas, preventivas e consciente por meio do setor público e privado assim como também de cada um de nós, que pode e deve lutar por esse ambiente, já que está na constituição e é direito de todos os cidadãos.

\section{Declaração de conflito de interesses}

Os autores declaram não haver conflito de interesses.

\section{Referências}

Amorim, E. L.C. Avaliação de impactos ambientais 1. Maceió: UFAL, 2011. Disponível em: <http://www.ctec.ufal.br/ professor/elca/AIA12011_2.htm>. Acesso em: 16 out. 2017.

Assunção, J.; Szerman, D.; Costa, F. Efeitos da construção de hidrelétrica na Amazônia sobre o desmatamento. 2016. Disponível em: <http://www.inputbrasil.org/wp-
content/uploads/2016/11/Resumo_UHEs_e_ Desmatamento_CPI.pdf>. Acesso em: 08 maio 2017.

Barbieri, A.F. Mudanças climáticas, mobilidade populacional e cenários de vulnerabilidade para o Brasil. Revista Interdisciplinar da Mobilidade Urbana, v. 19, n. 36, p. 95-112, 2011. Disponível em: <http://www.csem.org.br/remhu/index.php /remhu/article/view/249/231 >. Acesso em: 08 maio 2017.

Barbosa, G. S.; Rossi, A. M. G.; Drach, P. R. C. Análise de projeto urbano a partir de parâmetros urbanos sustentáveis: alteração morfológica de Copacabana e algumas de suas consequências climáticas (1930-19502010). Revista Brasileira de Gestão Urbana, v. 6, n. 3, p. 275-287, 2014.

Bedoya, S. P. O.; Prat, B. V.; Passos, R. C.; Carvalho, F. A. Indicadores para a avaliação do impacto na qualidade de vida de reassentados por barragens. Revista Científica Vozes do Vale, v. 12, n. 10, p. 1-14, 2016.

Brandão, I. L.S. A Usina Hidrelétrica de Balbina e as populações locais: um retrato da comunidade Carlos Augusto Nobre Ribeiro. Belém: Universidade Federal do Pará, 2010 (Dissertação de mestrado).

Brasil. Lei no 6.938, de 31 de agosto de 1981. Dispõe sobre a Política Nacional do Meio Ambiente, seus fins e mecanismos de formulação e aplicação, e dá outras providências. Disponível em: 
<http://www.planalto.gov.br/ccivil_03/leis/ L6938.htm>. Acesso em: 05 mar. 2017.

Brasil. Resolução CONAMA n ${ }^{\circ} 01$, de 23 de janeiro de 1986. Disponível em: <http://www.mma.gov.br/port/conama/legi abre.cfm?codlegi=2>. Acesso em: 07 maio 2017.

Brasil. Constituição da República Federativa do Brasil de 1988. Brasília: Senado Federal, 1988.

Brasil. Ministério das Cidades. Urbanização de favelas: a experiência do PAC. Brasília: Ministério das Cidades, Secretaria Nacional de Habitação, 2010.

Campos, S. F. C.; Macedo, L. M.; Elali, G. A. Uma casa ou um lar? Uma análise da relação dos residentes em um conjunto de habitações de interesse social com seu local de moradia. Anais do VI Seminário Nacional sobre Ensino e Pesquisa em Projeto de Arquitetura, Salvador, 2013.

Carmo, R. L. Urbanization, water and health in Brazil: Aspects of dengue fever epidemics. Anais da XXVI International Population Conference, IUSSP, Marrakech, 2009. Disponível em: <http://paa2011.princeton. edu/papers/112607>. Acesso em: 09 out. 2017.

Coelho, A. B.; Pedro, J. B. Cinco décadas de pesquisa habitacional no LNEC e a metodologia de APO. In: Ornstein, S. W.; Villa, S. B. (Orgs.). Qualidade ambiental na habitação: avaliação pós-ocupação. São Paulo: Oficina de Textos, 2013. p. 315-341.

Costa, D. R.; Cavalcante, L. I. C; Afonso, T. Remanejamento, reassentamento e adaptação dos moradores ao conjunto habitacional Jader Barbalho - AnanindeuaPA. Anais do Encontro Internacional e Nacional de Política Social, Vitória, 2016.

Cremonez, F. E.; Cremonez, P. A.; Feroldi, M.; Camargo, M. P.; Klajn, F. F.; Feiden, A. Avaliação de impacto ambiental: metodologias aplicadas no Brasil. Revista Monografias Ambientais, v. 13, n. 5, p. 3821-3830, 2014. https://doi.org/ 10.5902/2236130814689

FAO - Food and Agriculture Organization of the Unites Nations. Environmental impact assessment: Guidelines for FAO fiel projects. Roma: FAO, 2011. (EIA reports).

Farinaccio, A; Tessler, M. G. Avaliação de impactos ambientais no meio ambiente físico decorrentes de obras de engenharia costeira: uma proposta metodológica. Revista da Gestão Costeira Integrada, v. 10, n. 4, p. 419-434, 2010. https://doi.org/10.5894/ rgci210

Fearnside, P. M. Hidrelétricas na Amazônia: impactos ambientais e sociais na tomada de decisões sobre grandes obras. Manaus: INPA, 2015. v. 1.

Ferreira, L. P. F. Reassentamento dos atingidos por barragens limites da competência regulatória da ANEEL. Senatus: Cadernos da Secretaria de Informação e Documentação, v. 7, n. 2, p. 50-63, 2009. Disponível em: <http://www2.senado.leg.br/ bdsf/bitstream/handle/id/183234/0008724 58.pdf>. Acesso em: 15 set. 2017.

Freitas, G. F.; Oliveira, M. L. R.; Sousa, D. R. N. As transformações socioculturais acarretadas pelo reassentamento de famílias atingidas pela Barragem de Irapé no Vale do Jequitinhonha-Minas Gerais. Revista Caminhos de Geografia, v. 14, n. 48, p. 38-47, 2013. Disponível em: <http://www.seer.ufu.br/index.php/caminh osdegeografia/article/view/21063/14305>. Acesso em: 15 set. 2017.

Finucci, M. Metodologias utilizadas na avaliação do impacto ambiental para a liberação comercial do plantio de transgênicos. São Paulo: Faculdade de Saúde Pública da Universidade de São Paulo, 2010. (Dissertação de Mestrado).

Gil, A.C. Métodos e técnicas de pesquisa social. 6. ed. São Paulo: Atlas, 2008.

Gomes, M. P. Matriz de interação qualitativa de aspectos e impactos ambientais no seguimento de rochas ornamentais: estudo de caso. Revista Unirn, v. 8, n. 1-2, p. 135159, 2009.

Gerhard, T. E.; Silveira, D. T. (Org.). Métodos de pesquisa. Porto Alegre: Editora UFRGS, 2009.

Graim, R. M. T.; Felisbino, D. A.; Perdigão, A. K. A. V. Impacto causado pelo processo de remanejamento/reassentamento no idoso: o projeto Vila da Barca, Belém (PA). Revista Nacional de Gerenciamento de Cidades, v. 5 , n. 30, p. $90-103,2017$. https://doi.org/ 10.17271/2318847253020171542

IAIA - International Association for impact Assessment. The leading global network on impact assessment. 2016. Disponível em: <http://www.iaia.org/>. Acesso em: 15 mar. 2017. 
IBGE - Instituto Brasileiro de Geografia e Estatística. Estimativas da população residente no Brasil e unidades da federação com data de referência em $1^{\text {o }}$ de julho de 2017. Disponível em: <https://ww2.ibge.gov.br/home/estatistica/ populacao/estimativa2017/default.shtm>. Acesso em: 06 out. 2017.

Kaercher, J. A.; Schneider, R. C. S.; Klamt, R. A.; Silva, W. L. T.; Schmatz, W. L.; Szarblewski, M. S.; Machado, E. L. Optimization of biodiesel production for self-consumption: considering its environmental impacts. Journal of Cleaner Production, v. 46, p. 74-82, 2013. https://doi.org/10.1016/j.jclepro.2012.09.016

Leoneti, A. B.; Prado, E. L.; Oliveira, S. V. W. B. Saneamento básico no Brasil: considerações sobre investimentos e sustentabilidade para o século XXI. Revista de Administração Pública, v. 45, n. 2, p. 331-348, 2011. https://doi.org/10.1590/S0034-761220110 00200003

Leopold, L. B.; Clarke, F. E.; Hanshaw, B. B.; Balsley, J. R. A procedure for evaluating environmental impact. Washington: U.S. Geological Survey, 1971. (U.S. Geological Survey Circular, 645). Disponível em: <https://pubs.er.usgs.gov/publication/cir64 5>. Acesso em: 06 out. 2017.

Lermen, H. S.; Fisher, P. D. Percepção ambiental como fator de saúde pública em área de vulnerabilidade social no Brasil. Revista APS, v. 13, n.1, p.62-71. 2010. Disponível em: <https://aps.ufjf. emnuvens.com.br/aps/article/view/553/29 8>. Acesso em: 06 out. 2017.

Mendes, N. A. S.; Hespanhol, R. A. M. Impactos socioambientais de usinas hidrelétricas: algumas considerações. Revista Formação, v. 1, n. 10, p. 51-64, 2012. Disponível em: <http://revista.fct.unesp.br/index.php/form acao/article/viewFile/1111/1116>. Acesso em: 05 out. 2017.

Meneguzzo, I. S.; Chaicouski, A. Reflexões acerca dos conceitos de degradação ambiental, impacto ambiental e conservação da natureza. Geografia, v. 19, n. 1, p. 181185, 2010. Disponível em: <http://www.uel.br/revistas/uel/index.php/ geografia/article/view/2593/5061>. Acesso em: 05 out. 2017.

Miranda Neto, J. Q. Reassentamento da população urbana diretamente afetada pelo empreendimento hidrelétrico de Belo Monte em Altamira-PB. Revista Nacional de Gerenciamento de Cidades, v. 2, n. 13, p 4357, 2014. https://doi.org/10.17271/231884 722132014766

Norte Energia. Projeto Básico Ambiental da Usina Hidrelétrica de Belo Monte: Planos programas e projetos. 2011.

Norte Energia. Projeto Básico Ambiental da Usina Hidrelétrica de Belo Monte: Andamento dos Programas/Projetos/ Condicionantes Ambientais. 2015.

Oliveira, A. D.; Pietrafesa, P. J.; Barbalho, S. G. M. Manutenção da biodiversidade e o hotspots no Cerrado. Revista Caminhos de Geografia, v. 9, n. 26, p. 101-114, 2008. Disponível em: <http://www.seer.ufu.br/ index.php/caminhosdegeografia/article/vie w/15700/8881>. Acesso em: 20 out. 2017.

Oliveira, A. C.; Conceição, R. S.; Horizonte, J. S. Impactos de grandes obras na dinâmica urbana de crianças e adolescentes: a implantação da Usina de Belo Monte. Ponto e Vírgula, v. 1, n. 16, p.185-205, 2014. Disponível em: <https://revistas.pucsp.br/ index.php/pontoevirgula/article/view/2524 9/18059>. Acesso em: 20 out. 2017.

Oliveira, A. C.; Conceição, R. S. Impactos sociais das políticas compensatórias da usina de Belo Monte: dinâmicas de afetação às crianças e aos adolescentes. Revista Direito $\begin{array}{llll}\text { e Práxis, } & \text { v. 7, } & \text { n. 14, p. 8-34, } 2016 .\end{array}$ https://doi.org/10.12957/dep.2016.19146

Parente, T. G; Miranda, C. M. Impactos socioculturais e gênero nos reassentamentos da Usina Luís Eduardo Magalhães-TO. Varia História, v. 30, n. 53, p.557-570, 2014. https://doi.org/10.1590/S0104-87752014 000200011

PMA - Prefeitura Municipal de Altamira. Plano Diretor de Altamira. Altamira, 2011. Disponível em: <http://altamira.pa.gov.br/ site/category/plano-diretor/>. Acesso em: 05 out. 2017.

Pozzatti Junior, A.; Ribeiro, L. I. Entre os direitos humanos e a pressão política: o caso Belo Monte no sistema interamericano. Revista Direitos Humanos e Democracia, v. $2, \quad$ n. $4, \quad$ p. 107-142, 2014. https://doi.org/10.21527/2317-5389.2014. 4.107-142

Sánchez, L. E. Avaliação de impacto ambiental: conceitos e métodos. São Paulo: Oficina de Textos, 2008. 
Sánchez, L. E. Avaliação de impacto ambiental: conceitos e métodos. 2. ed. São Paulo: Oficina de Textos, 2013.

Santos, H. J. D; Fiori, S. Evolução da avaliação de impacto ambiental para empreendimentos rodoviários: uma análise descritiva e aplicada. Passo Fundo: UPF, 2010.

Silveira, M. A. Contribuição do setor saúde aos processos de licenciamento ambiental de empreendimentos: primeiras aproximações. Brasília: Universidade de Brasília, 2008. (Dissertação de mestrado).

Walter, T.; Anello, L.F.S. A educação ambiental enquanto medida mitigadora e compensatória: uma reflexão sobre os conceitos intrínsecos na relação com o Licenciamento Ambiental de Petróleo e Gás tendo a pesca artesanal como contexto. Ambiente \& Educação, v. 17, n. 1, p. 73-98, $2012 . \quad$ Disponível em: $<$ https://www.seer.furg.br/ambeduc/article /view/2657/1669>. Acesso em: 05 out. 2017.

Informação da Licença: Este é um artigo Open Access distribuído sob os termos da Licença Creative Commons Attribution, que permite uso irrestrito, distribuição e reprodução em qualquer meio, desde que a obra original seja devidamente citada. 